\title{
Effect of Silicon, Titanium, and Zirconium Ion Implantation on NiTi Biocompatibility
}

\author{
L. L. Meisner, ${ }^{1}$ A. I. Lotkov, ${ }^{1}$ V. A. Matveeva, ${ }^{2}$ \\ L. V. Artemieva, ${ }^{2}$ S. N. Meisner, ${ }^{1}$ and A. L. Matveev $^{2}$ \\ ${ }^{1}$ Institute of Strength Physics and Materials Science, SB RAS, Akademichesky 2/4, Tomsk 634021, Russia \\ ${ }^{2}$ Institute of Chemical Biology and Fundamental Medicine, SB RAS, Lavrent'eva 8, Novosibirsk 630090, Russia
}

Correspondence should be addressed to L. L. Meisner, meisner2l@yahoo.com

Received 31 March 2011; Accepted 19 September 2011

Academic Editor: W. Ensinger

Copyright () 2012 L. L. Meisner et al. This is an open access article distributed under the Creative Commons Attribution License, which permits unrestricted use, distribution, and reproduction in any medium, provided the original work is properly cited.

The objective of the work was to study the effect of high-dose ion implantation (HDII) of NiTi surface layers with $\mathrm{Si}$ Ti, or Zr, on the NiTi biocompatibility. The biocompatibility was judged from the intensity and peculiarities of proliferation of mesenchymal stem cells (MSCs) on the NiTi specimen surfaces treated by special mechanical, electrochemical, and HDII methods and differing in chemical composition, morphology, and roughness. It is shown that the ion-implanted NiTi specimens are nontoxic to rat MSCs. When cultivated with the test materials or on their surfaces, the MSCs retain the viability, adhesion, morphology, and capability for proliferation in vitro, as evidenced by cell counting in a Goryaev chamber, MTT test, flow cytometry, and light and fluorescence microscopy. The unimplanted NiTi specimens fail to stimulate MSC proliferation, and this allows the assumption of bioinertness of their surface layers. Conversely, the ion-implanted NiTi specimens reveal properties favorable for MSC proliferation on their surface.

\section{Introduction}

Today, the treatment of ischemic heart disease (IHD) is still one of the most urgent and foreground problems of the world and national healthcare. Among modern methods of IHD correction is intracoronary stenting $[1,2]$.

The treatment of a human vascular system with stentsendoprostheses-for increasing the lumen of vessels and keeping them open requires application of materials with high strength and high elastoplastic characteristics. Alloys based on titanium nickelide, or NiTi-based alloys, match in full measure the above requirements demonstrating superelasticity or so-called shape memory effect-the capability for accumulation of high strain (4-6\%) and its reversible return without fracture [3-5].

Particular attention should be given to the surface treatment of endoprostheses. The surface of endoprostheses must have minimum adhesion to preclude the risk of growth of plain muscular tissue in the lumen of an implant whilst being biologically compatible and tolerable to medicines with which the implant surface will contact.
It is apparent that for the biocompatibility of medical materials to increase, it suffices to create or modify the properties of their surface or thin surface layers. An efficient way of improving the physicochemical and mechanical surface characteristics of microsurgical tools, and increasing their biocompatibility is ion and electron beam surface modifications and a combination of these methods with deposition of thin coatings made of biotolerable chemical elements or composites $[6,7]$. Surface conditioning of metal materials in several successive stages_etching, mechanical grinding and polishing, and electropolishing-is often final for implants. At the same time, this surface conditioning precedes coating deposition or appropriate surface modification and eventually determines the quality of a medical tool [810]. However, detailed data on the effect of the individual treatment methods listed above or their combinations on the NiTi biocompatibility are scantily available.

A reliable method of preclinical biocompatibility assessment is testing of implant materials with cell cultures. In vitro testing allows us to study the action of a test material on biological properties of mammalian cells. These 
examinations are conducted with CCL1, CCL 163, Vero, and other long-term cell lines, cultures of fibroblasts, lymphocytes, macrophages, epithelial cells, and germ or diploid cells of humans and animals [11]. The choice of a stent material is normally based on its examination with blood cells, for example, for platelet adhesiveness to its surface. At the same time, the problem of long-term implantation effects and possible growth of fibromuscular tissue on stent surfaces requires examination of the surfaces on long-term cell cultures. Now, the properties of implants are studied on mesenchymal stem cells (MSCs) [12] with their inherent differentiation of bone, connective, and muscular tissues in a cell, and also on other mesodermal cells [13]. The capability of MSCs for proliferation in vitro [14] allows the use of MSCs in cytotoxicity assays of chemical compositions of implants and analyses of their surface morphology. These studies make it possible to determine the conditions necessary for successful cell proliferation, for example, in regeneration of osseous defects [14] or vascular walls [15], and for maximum possible surface resistance of a biocompatible material in cell proliferation.

The objective of the work is to study the biocompatibility of NiTi specimens treated by special mechanical, electrochemical, and HDII methods and their effect on the proliferation of mesenchymal stem cells and cytotoxicity.

\section{Materials, Surface Treatment Methods, and Research Techniques}

2.1. Materials and Surface Treatment Methods. The materials to be tested were two series each of 80 flat-rolled specimens of commercial TiNil alloy (MATEKS, Russia). The NiTi specimens for physicochemical tests (14 specimens in a series) and biological tests ( 66 specimens in a series) were flat plates of dimensions $1.6 \times 10 \times 15 \mathrm{~mm}^{3}$. For biological tests, the specimens were treated to have two types of surfaceNiTi-A and NiTi-B.

Surface treatment A it included two steps:

Step 1. Etching in a solution $\left(\mathrm{HNO}_{3}\right.$ and $\mathrm{HF}$ in a ratio of 3/1) heated to $T=50^{\circ} \mathrm{C}$ for $3 \mathrm{~min}$;

Step 2. Metallic-luster electropolishing in a solution $\left(\mathrm{CH}_{3} \mathrm{COOH}\right.$ and $\mathrm{HClO}_{4}$ in a ratio of 3/1) cooled down to $T=$ $273 \mathrm{~K}\left(0^{\circ} \mathrm{C}\right)$ at a voltage $U=30 \mathrm{~V}$.

Surface treatment B it included three steps:

Step 1. Etching in a solution $\left(\mathrm{HNO}_{3}\right.$ and $\mathrm{HF}$ in a ratio of 3/1) heated to $T=50^{\circ} \mathrm{C}$ for $3 \mathrm{~min}$;

Step 2. High-luster mechanical polishing on a Sapphirre 550 grinder-polisher (ATM GMBH, Germany). The specimens were placed in special metal cups, and the cups were filled with epoxy resin and kept at room temperature $\left(T_{r}\right)$ within a day for complete epoxy solidification. Thereafter, the specimens were grinded on silicon carbide grinding foil (ATM GMBH, Germany) with a gradual decrease in granularity from 100 to $1.2 \pm 0.3 \mu \mathrm{m}$ and supply of water heated to $T=303 \mathrm{~K}\left(30^{\circ} \mathrm{C}\right)$ to the grinding surface. Water served as a lubricant and simultaneously as a heater to preclude the appearance of a martensite phase in the process. The rate of rotation of the grinding table was $v=150 \mathrm{rpm}$; the grinding time for each level of granularity was $\Delta t=5-$ $8 \mathrm{~min}$ (to the point of surface smoothening). At the final stage, the specimens were polished on a polishing cloth alpha perforated paper with a Bio Diamant Cameo lubricant (LAM PLAN, France) of abrasivity $9 \mu \mathrm{m}$. The rate of rotation of the polishing table was $v=150 \mathrm{rpm}$; the high-luster polishing time was $\Delta t=2-5 \mathrm{~min}$.

Step 3. Metallic-luster electropolishing in a solution $\left(\mathrm{CH}_{3} \mathrm{COOH}\right.$ and $\mathrm{HClO}_{4}$ in a ratio of $\left.3 / 1\right)$ cooled down to $T=$ $273 \mathrm{~K}\left(0^{\circ} \mathrm{C}\right)$ at a voltage $U=30 \mathrm{~V}$.

Ion implantation of the specimens was realized on a DIANA-3 (ISPMS SB RAS, Tomsk, Russia [16-18]) ion implanter with $\mathrm{Si}, \mathrm{Ti}$, and $\mathrm{Zr}$ single-component pulsed ion beams (using iodide $\mathrm{Ti}$ and $\mathrm{Si}$ cathodes) under the conditions of oilless pumping and high vacuum $\left(\sim 10^{-6} \mathrm{~Pa}\right)$. This method is known as high-dose ion implantation (HDII) [19-22]. The ion beam treatment was in implantation of NiTi surface layers with $\mathrm{Si}, \mathrm{Ti}$, or $\mathrm{Zr}$ ions of fluence $D=$ $2 \times 10^{17} \mathrm{~cm}^{-2}$ at an average accelerating voltage of $60 \mathrm{kV}$ and pulse repetition frequency of $50 \mathrm{~Hz}$. The temperature of the specimens in ion implantation was no greater than 373$424 \mathrm{~K}$. The specimens subjected to ion beam treatment were NiTi-A and NiTi-B specimens differing in roughness such that for biological tests we prepared eight series of the NiTi specimens differing in chemical composition, topography, and roughness. The marking of the series of the specimens with differently modified surfaces used in the work are given in Table 1.

The investigations were made on the equipment of the Shared Use Center (SUC) "Nanotech" of ISPMS SB RAS. The surface morphology was analyzed on the a LEO EVO 50 scanning electron microscope (Zeiss, Germany) and an Axiovert 200 MAT optical microscope (Zeiss, Germany) with brightand dark-field imaging and differential interference contrast (DIC) for visualization of objects with minimum differences in surface roughness height. The phase composition of the specimens was analyzed on a DRON-7 X-ray diffractometer (Burevestnik, Russia). Layer-by-layer elemental analysis was performed on a Shkhuna-2 Auger spectrometer (NR TPU, Russia). The diameter of a probing electron beam was $\sim 1 \mu \mathrm{m}$ and the electron energy was $\sim 3 \mathrm{keV}$. In recording of Auger spectra, the electron beam raster was $10 \times 10 \mu \mathrm{m}^{2}$. The energy resolution of the analyzer was $0.7 \%$. The target material was sputtered layer by layer with an Ar ion beam of energy $3 \mathrm{keV}$ and diameter $1 \mathrm{~mm}$. The sputtering rate of the target material was $2-3 \mathrm{~nm} / \mathrm{min}$. Analysis of the surface roughness and surface treatment quality and visualization of surface defects and fracture traces of the materials was performed on a New-View 5000 3D optical interferometerprofilometer (Zygo, USA) with a surface profile accuracy of $\pm 1 \mathrm{~nm}$. The microhardness of surface layers of the specimens was measured on a DM8 microhardness tester (Affri, Italy). 
TABLE 1: Types and description of surface treatment of the NiTi specimens.

\begin{tabular}{lclc}
\hline Type of treatment & $\begin{array}{c}\text { Substrate material and type of } \\
\text { previous surface treatment }\end{array}$ & Finishing treatment & Specimen marking \\
\hline 1 & 2 & 3 & 4 \\
\hline \multirow{2}{*}{ NiTi } & Step 1: etching & NiTi-A \\
& Step 2: electropolishing & NiTi-B \\
\hline \multirow{3}{*}{ NiTi } & Step 1: etching & Step 2: mechanical polishing \\
& Step 3: electropolishing & NiTi-AG \\
\hline$G$ & NiTi-A & Step 4: HDII & NiTi-BG \\
\hline$H$ & NiTi-A & with Zr, $D_{\mathrm{Zr}}=2 \times 10^{17} \mathrm{~cm}^{-2}$ & NiTi-AH \\
& NiTi-B & Step 4: HDII & NiTi-BH \\
\hline$J$ & NiTi-A & with Ti, $D_{\mathrm{Ti}}=2 \times 10^{17} \mathrm{~cm}^{-2}$ & NiTi-AJ \\
& NiTi-B & with Si, $D_{\mathrm{Si}}=2 \times 10^{17} \mathrm{~cm}^{-2}$ & NiTi-BJ \\
\hline
\end{tabular}

TABLE 2: Doping element concentration in the ion-implanted surface layers and average surface roughness (roughness height parameter) of the NiTi specimens.

\begin{tabular}{|c|c|c|c|c|}
\hline Type of treatment & Specimen marking & Ion type, fluence & $\begin{array}{c}\text { Doping (implanted) concentration, } \\
\text { at. \% }\end{array}$ & $\begin{array}{l}\text { Average roughness (roughness } \\
\text { height parameter) } R_{a}, \mu \mathrm{m}\end{array}$ \\
\hline A & NiTi-A & \multirow{2}{*}{ Unimplanted } & - & 0.972 \\
\hline B & NiTi-B & & - & $0.047-0.061$ \\
\hline \multirow[t]{2}{*}{$\bar{G}$} & NiTi-AG, & $\mathrm{Zr}$, & $>0.2$ & $0.860-0.940$ \\
\hline & NiTi-BG & $D_{1}=2 \times 10^{17} \mathrm{~cm}^{-2}$ & & $0.025-0.041$ \\
\hline \multirow[t]{2}{*}{$\mathrm{H}$} & NiTi-AH, & $\mathrm{Ti}$ & $>0.3$ & $0.936-1.272$ \\
\hline & NiTi-BH & $D_{2}=2 \times 10^{17} \mathrm{~cm}^{-2}$ & $\begin{array}{l}\text { (relative to its concentration before } \\
\text { irradiation) }\end{array}$ & $0.026-0.035$ \\
\hline \multirow[t]{2}{*}{$\mathrm{J}$} & NiTi-AJ, & $\mathrm{Si}$, & $>0.58$ & $0.892-0.921$ \\
\hline & NiTi-BJ & $D_{3}=2 \times 10^{17} \mathrm{~cm}^{-2}$ & & $0.033-0.039$ \\
\hline
\end{tabular}

The specimens were examined in vitro on rat marrow mesenchymal stem cells of the $2^{\text {nd }}$ passage. The cells were cultivated in an $\alpha$-MEM medium containing $10 \%$ of fetal calf serum, $200 \mathrm{mM}$ of L-glutamine and $100 \mu \mathrm{g} / \mathrm{mL}$ of gentamicin (Biolot, Russia) in 6- and 12-well plastic trays (Nunc, Denmark) at $37^{\circ} \mathrm{C}$ in an atmosphere with $5 \%$ of $\mathrm{CO}_{2}$ and with a saturation moisture content. In the tests, the specimens were in direct contact with the MSCs. The cell viability was determined by cell counting in a Goryaev chamber according to [11] and in an MTS assay [23] according to [24].

The effect of the chemical composition and properties of the NiTi surface on the proliferation of MSCs cultivated in vitro with the differently modified $\mathrm{NiTi}$ specimens was determined from the characteristic properties of MSCs: proliferation and morphology [13]. The cytotoxic action of the specimens on rat marrow MSCs was estimated from the viability of the cells cultivated with the test specimens for $72 \mathrm{~h}$ and 7 and 14 days. For this study, two types of tests were performed.

Test Type I. The cells were seeded into 6-well trays at a density of $50 \times 10^{3} \mathrm{cell} / \mathrm{cm}^{2}$, and 24 hours later, the specimens were placed in the wells and the cultivation was continued. After 72 hours, the cell viability was estimated through cell counting in the Goryaev chamber and in the MTT test (3-[4,5-dimethylthiazol-2-yl]-2,5-diphenyl tetrazolium bromide). For cell counting in the Goryaev chamber, the attached cells were removed with a $0.25-\%$ trypsin-EDTA solution (Biolot, Russia) within $2-5 \mathrm{~min}$. The cells were counted in 150 large squares. For the MTT-test, the optical density of eluate aliquots was measured on an Apollo-8 LB 912 microplate photometer (Berthold Technologies, GmbH and Co, KG, Germany) in four iterations at a wavelength of 620 and $570 \mathrm{~nm}$ to preclude the effect of cellular debris. The cell viability was estimated in percent. Cell control wells were wells with no specimen (with cells only).

Test Type II. The cells were seeded into 6-well trays at a density of $5 \times 10^{3} \mathrm{cell} / \mathrm{cm}^{2}$, and 24 hours later, the specimens were placed in the wells and the cultivation was continued. After 7 and 14 days, the cell viability was determined through cell counting in the Goryaev chamber and in the MTT test as described above. Cell control wells were wells with no specimen (with cells only). 
The morphology of the cells cultivated with the modified NiTi specimens was determined on the well surfaces using an Axiovert 40C optical microscope (Carl Zeiss, Germany).

For evaluation of the efficiency of MSC proliferation on the specimen surface, the specimens were placed in 12-well trays and a suspension of cells rated at $5 \times 10^{3} \mathrm{cell} / \mathrm{cm}^{2}$ was transferred into the wells. After 14, 18, and 22 days, the specimens were transferred into fresh wells and rinsed from unattached cells; the number of cells on the specimens was estimated through cell counting in the Goryaev chamber after removal of cells from the specimens as described above.

For visualization of cells and estimation of their morphology and population density on the specimens, MSCs of the second passage were used; they were transfected with a pEGFP-N1 plasmid DNA (Clontech Laboratories, Inc., USA) containing a green fluorescent protein (GFP) gene with the use of a TurboFect transfection reagent (Fermentas, Life Sciences Inc., Canada) as specified by the manufacturer. Before examination on an Axioimager M1 fluorescence microscope (Carl Zeiss, Germany) with filters number 9 and 49 , the culture medium was stained with DAPI $(1 \mathrm{mg} / \mathrm{mL})$ and incubated for $10 \mathrm{~min}$ as prescribed by the manufacturer (Sigma, USA). Images were taken with a Sanyo 6975 CCD color camera.

Statistical data processing was by a standard procedure [25]. The confidence intervals of the general mean was estimated for $n=6$.

\section{Research Results and Discussion}

3.1. Structural-Phase States of the NiTi Surface Layers before and after Ion Implantation. X-ray diffraction data on the phase composition and parameters of the fine crystalline structure in NiTi near-surface layers before and after ion implantation are presented in Table 2. It is seen from Table 2 and diffraction patterns in Figure 1 that the X-ray diffraction analysis failed to reveal any change in the phase composition beneath the ion-implanted layer, and this is explained by the low radiation dose and hence by the low interstitial ion density. The phase composition in near-surface layers of all specimens is the same and is characterized by $\sim 95 \mathrm{vol} . \%$ of the $\mathrm{B} 2$ phase and $\sim 5$ vol. $\%$ of the $\mathrm{Ti}_{4} \mathrm{Ni}_{2} \mathrm{O}_{\mathrm{X}}$ phase. The lattice parameter of the $\mathrm{B} 2$ phase is $a_{\mathrm{B} 2}=3.007 \pm 0.007 \AA$ and corresponds to its composition- $\mathrm{Ti}_{49} \mathrm{Ni}_{51}$. The diffraction patterns of the specimens before (Figure 1, curve 1) and after (Figure 1, curves 2-4) ion implantation reveal very intense peaks $(110)_{\mathrm{B} 2}$ compared to the peaks $(211)_{\mathrm{B} 2}$ and $(310)_{\mathrm{B} 2}$, the absence of the peak $(200)_{\mathrm{B} 2}$, and the presence of superstructural peaks $(111)_{\mathrm{B} 2}$ and $(221)_{\mathrm{B} 2}$ due to the texture of the initial B2 phase with a texture axis close to $\langle 110\rangle_{\mathrm{B} 2}$ which remains unchanged after ion implantation.

When implanted with $\mathrm{Ti}$ and $\mathrm{Zr}$ metal ions, the NiTi surface layers are characterized by plane stress states which are not observed in the specimens before irradiation. On the contrary, elastic stress states in the near-surface layer implanted with Si ions are detected neither by symmetric imaging, which allows estimation of integral characteristics, nor by asymmetric imaging with a decrease in glancing angle

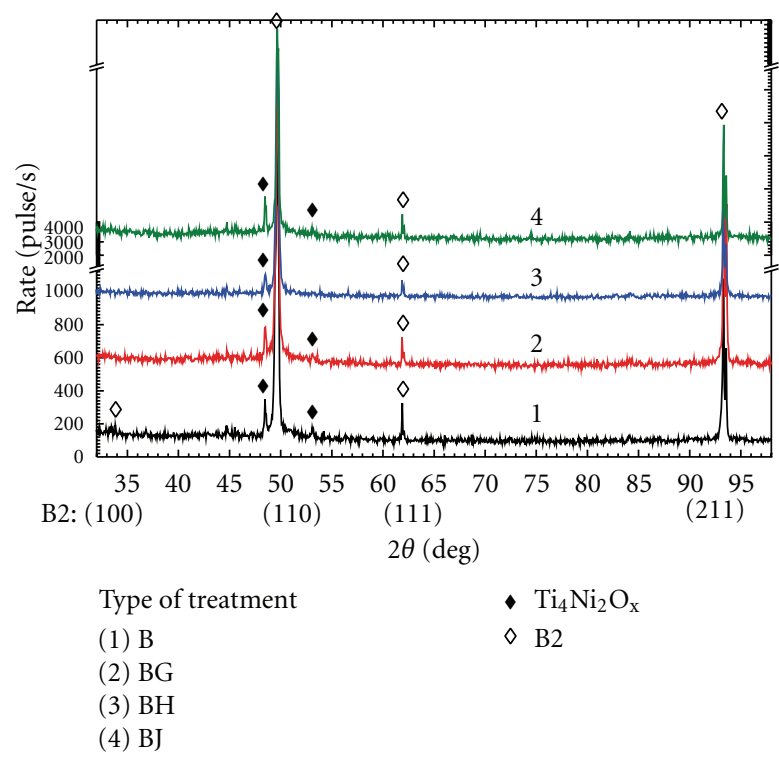

FIgure 1: Diffraction patterns of the NiTi specimens from the side of the surface treated by different methods: (1) electropolished mirror NiTi-B surface; (2), (3), (4) NiTi-B surface implanted with $\mathrm{Zr}-(\mathrm{BG}), \mathrm{Ti}(\mathrm{BH})$, and $\mathrm{Si}(\mathrm{BJ})$ ion beams, respectively.

to $\alpha=0.4^{\circ}$. This result is very important because surface activation of material, including that through creating elastic stress states in its surface layers, affects both the corrosion resistance and the biocompatibility of the material.

3.2. Physicochemical Surface Properties of the NiTi Specimens before and after Ion Implantation. For the surface layers of the NiTi specimens to have the same initial chemical composition before ion beam treatment, the specimens were finished by electropolishing in the same electrolyte and in the same polishing mode. Figure 2 shows the indepth element concentration distribution obtained by Auger electron spectroscopy (AES) for the NiTi specimens before (Figure 2(a)) and after ion beam irradiation (Figures 2(b)$2(\mathrm{~d}))$. It is seen that before ion beam irradiation, a NiTi surface layer of thickness $5-10 \mathrm{~nm}$ contains $60-40$ at. \% of carbon and 20-10 at. \% of oxygen the concentrations of which decrease almost to zero at a depth of $\sim 40-50 \mathrm{~nm}$. These elements participate in the formation of a biologically inert oxide-carbide film [26] typically depleted in nickel compared to its concentration in deeper NiTi layers, and this film can thus be a barrier layer on the path of metal ion penetration into the surrounding biomedium. After ion beam irradiation with rather small close accumulated doses (Table 1), irrespective of the type of an implanted ion, the outer layer of the specimens is enriched with up to 50-60 at. \% of oxygen uniformly distributed in the layer at a depth from 15 to $\sim 25 \mathrm{~nm}$, and what is more important, it is totally free (at the sensitivity level of the device) of nickel. In going deep to $\sim 5 \mathrm{~nm}$, the oxygen concentration decreases steeply to $\sim 10$ at. $\%$, and in the following layer of thickness $30-50 \mathrm{~nm}$, it hardly varies. On contrary, the percentage of carbon atoms on the irradiated specimen surface decreases two-three times 


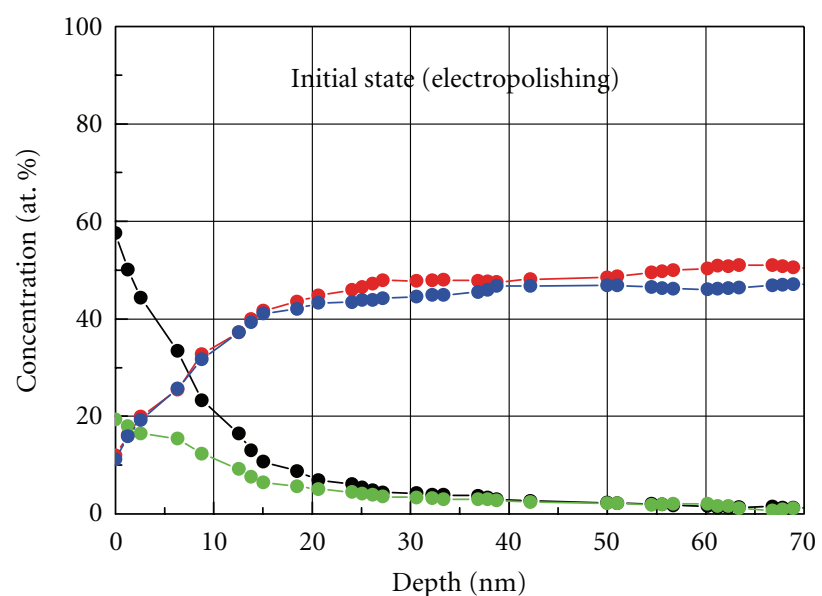

(a)

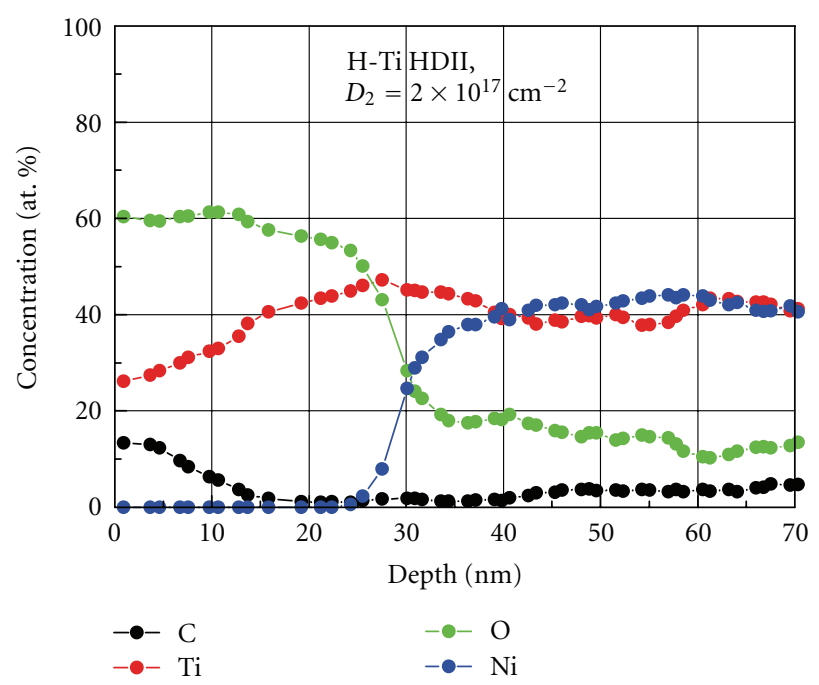

(c)

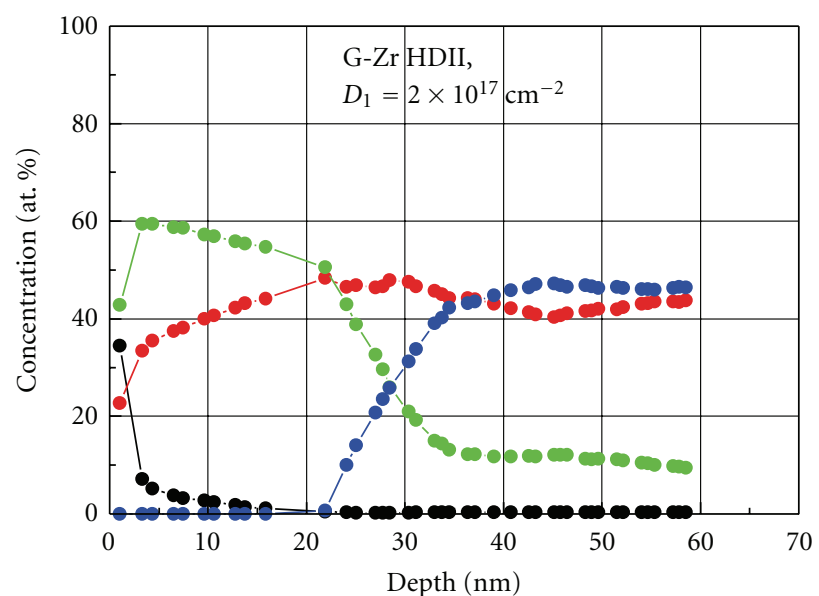

(b)

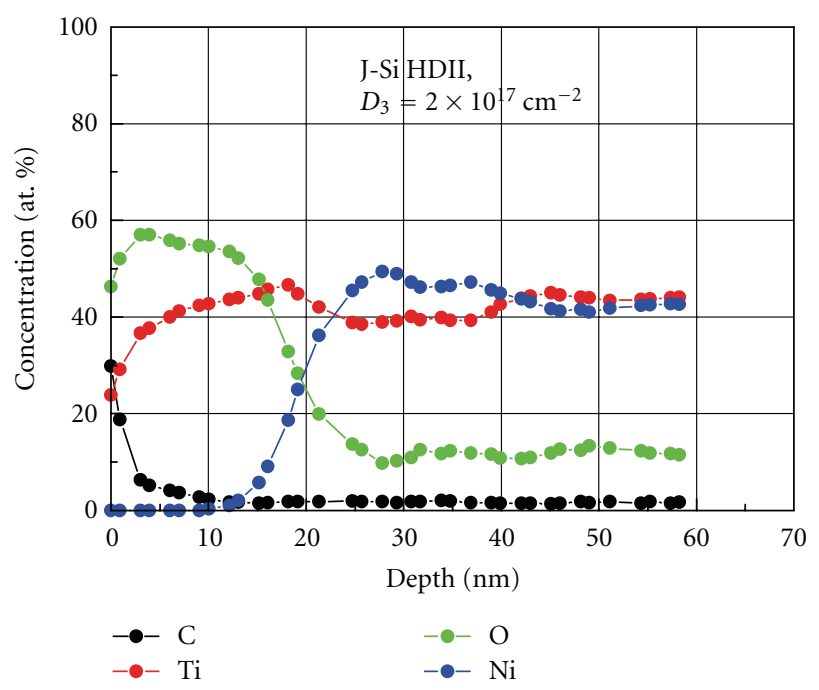

(d)

FIgURE 2: Chemical (elemental) composition of the NiTi specimen surfaces before (a) and after modification with Zr (b), Ti (c), and Si (d) ion beams. Auger electron microscopy.

and rapidly vanishes even at a depth of $\sim 10 \mathrm{~nm}$. In other words, the results of AES analysis demonstrate that ion beam modification with any ion type used in the work ensures oxygenation of a NiTi surfaces layer of total thickness $h \approx$ $100 \mathrm{~nm}$ such that an oxide film containing only a small amount of carbon and totally free of nickel is formed on the surface of the specimens. It should be noted that in individual cases where a NiTi-based implant is used under no mechanical load, its surface suffices to have an oxide-carbide layer of thickness $10-30 \mathrm{~nm}$ to provide complete passivation of the NiTi alloy $[27,28]$.

The effect of Ni depletion of NiTi surface layers (down to compete $\mathrm{Ni}$ removal from these layers) after ion beam treatment was observed earlier in [29-31]. In our viewpoint, this effect owes not to selective $\mathrm{Ni}$ sputtering from the surface, as might appear at first sight from the chemical element distribution curves obtained by the AES method
(Figures 2(b)-2(d)), but mainly to the following two factors. According to the data of electron-positron annihilation (EPA) spectroscopy [32], the vacancy formation energy $\left(E_{v}\right)$ on the sublattices of titanium and nickel in the B2 phase is $E_{v, \mathrm{Ti}}=(0.97 \pm 0.05) \mathrm{eV}$ and $E_{v, \mathrm{Ni}}=(0.78 \pm 0.02) \mathrm{eV}$, respectively. It was found that in the $\mathrm{B} 2$ phase stability region, the concentration of equilibrium vacancies on the Ni sublattice is much higher than that on the Ti sublattice: $C_{v, \mathrm{Ni}}=1 \times$ $10^{-9}$ and $C_{v, \mathrm{Ti}}=1 \times 10^{-12}$, respectively; the conclusion was that the diffusion mechanism in TiNi is of vacancy nature. These results suggest that $\mathrm{Ni}$ atoms are thus most mobile, because the higher vacancy concentration on their sublattice gives them priority to move over it. On the other hand, one of the most common effects of surface irradiation of solids is the high concentration of nonequilibrium defects, primarily radiation-induced vacancies, in near-surface layers [33]. A way to drive this nonequilibrium system to thermodynamic 


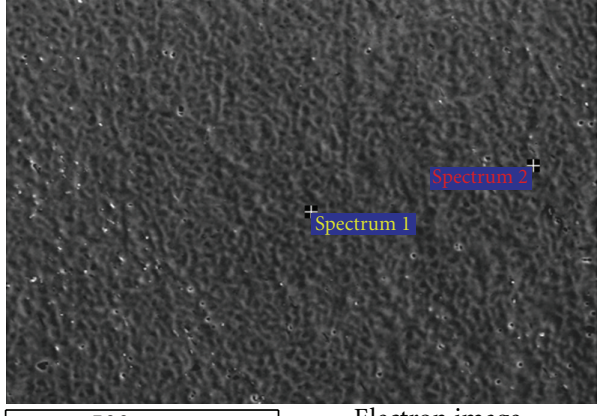

$500 \mu \mathrm{m}$

(a)

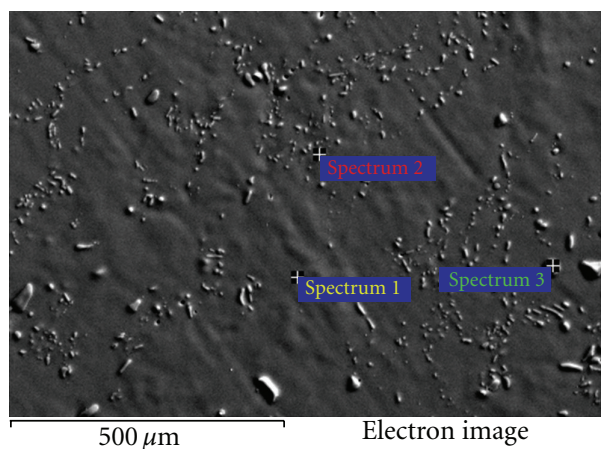

(c)

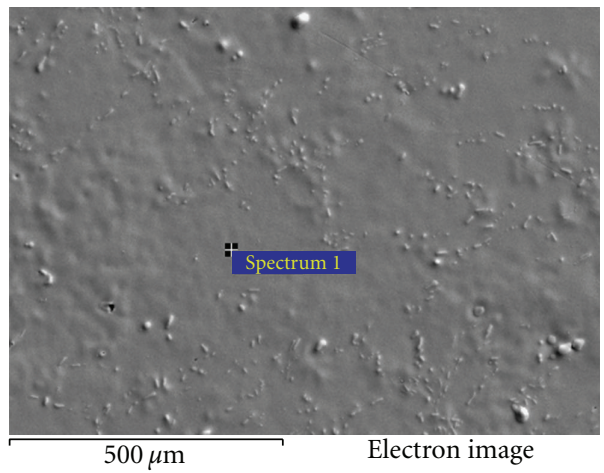

(e)

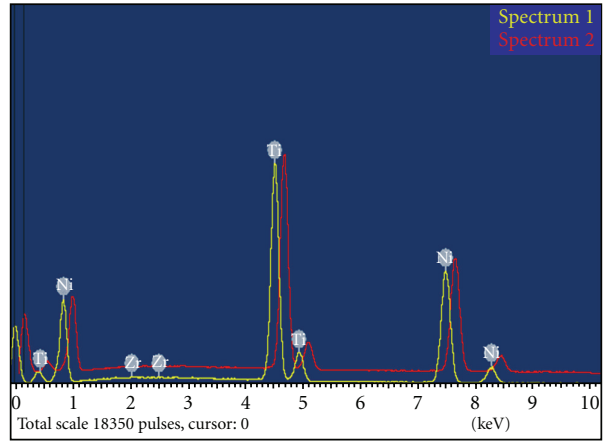

(b)

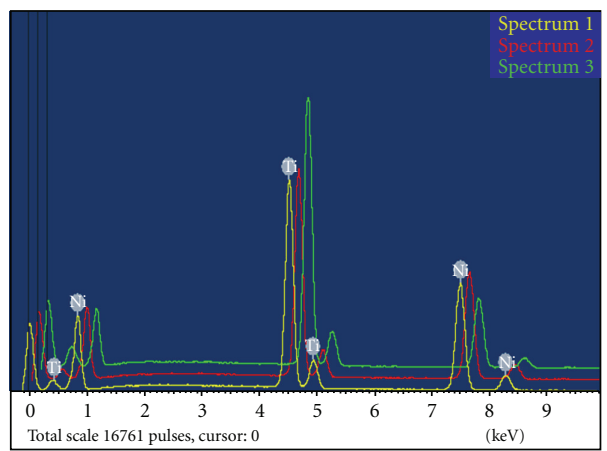

(d)

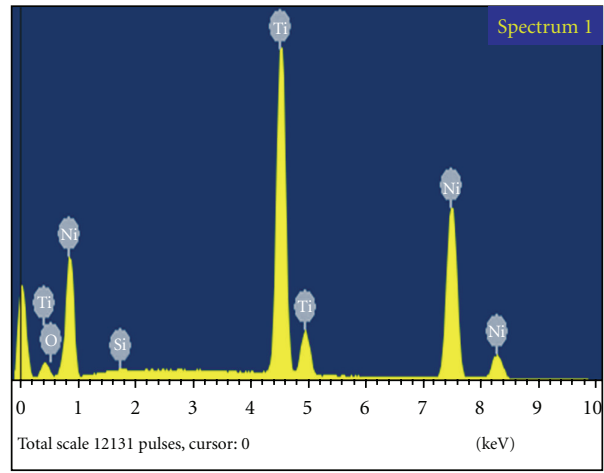

(f)

Figure 3: SEM images of the surface and X-ray spectra for the ion-implanted NiTi specimens: (a), (b): Zr ions (NiTi-BG), (c), (d): Ti ions (NiTi-BH), and (e), (f): Si ions (NiTi-BJ).

equilibrium is in redistribution of vacancies on the $\mathrm{Ti}$ and Ni sublattices and their drift toward the main sink- to the surface of the solid-with simultaneous radiation-induced (ascending) diffusion of target ( $\mathrm{Ti}$ and $\mathrm{Ni}$ ) and interstitial (Me) atoms in a direction opposite to the surface. For titanium nickelide, the higher mobility of $\mathrm{Ni}$ atoms is bound to provide more pronounced redistribution of $\mathrm{Ni}$ atoms in the modified layer compared to that of Ti atoms, which is what we actually observed after ion beam irradiation, and this eventually leads to release of Ni from a surface layer of depth 20-30 nm.

The AES method failed to detect the implanted chemical elements in the surface layers due to the small radiation dose.
Therefore, the concentration of these elements was estimated in energy dispersive microanalysis. According to the analysis, the doping element concentration in the ion-implanted layer is no greater than 0.5 at. \% (Table 2, Figure 3). It should be noted that the highest doping element concentration in the surface layer is found for the lightest among the implanted matters silicon whose concentration at a smaller accumulated dose is almost twice that of titanium and zirconium.

3.3. Surface Morphology and Roughness of the NiTi Specimens before and after Ion Implantation. Analysis of the surface morphology of the NiTi specimens after chemical treatment 

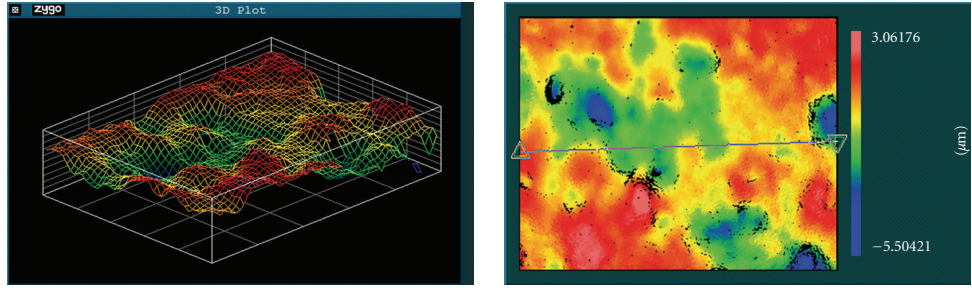

(a)
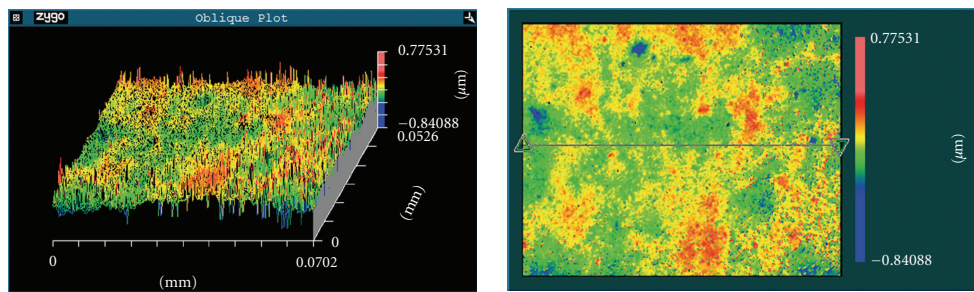

(b)
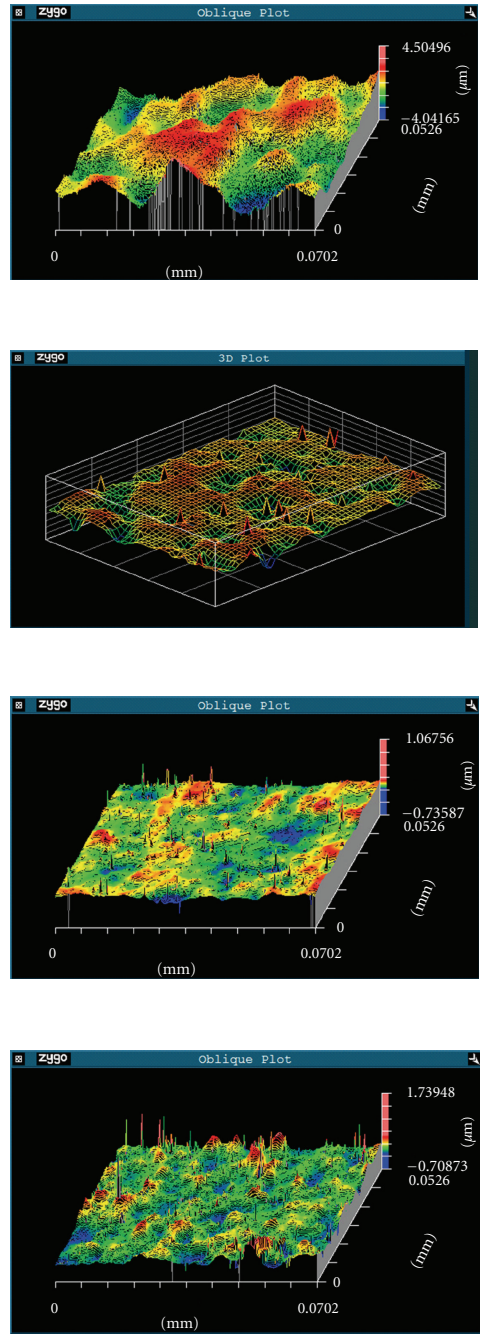

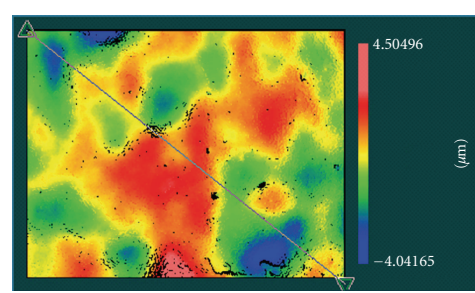

(c)

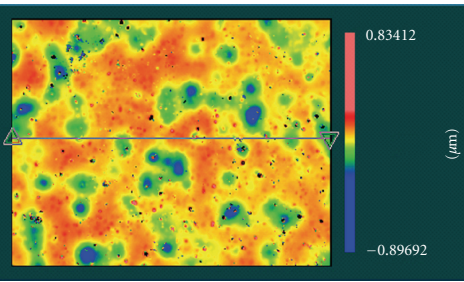

(d)

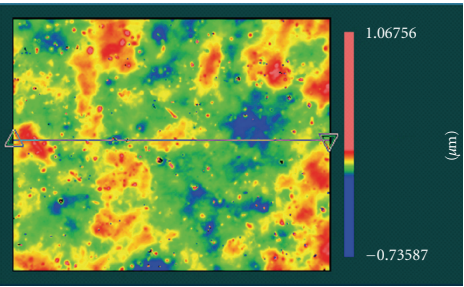

(e)

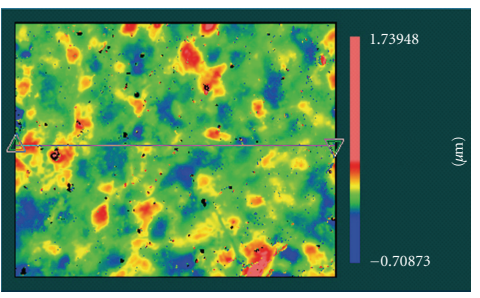

(f)
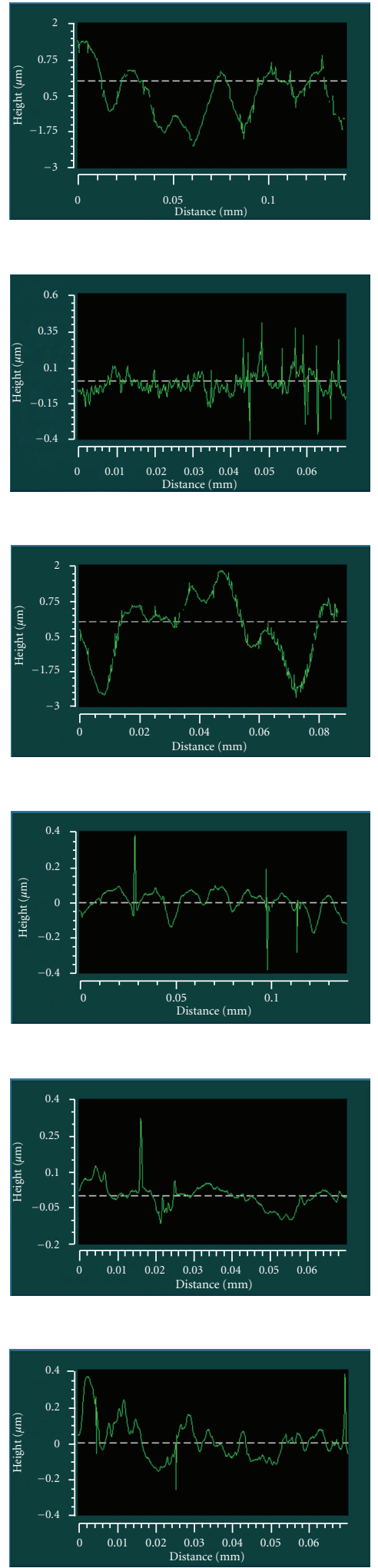

Figure 4: From left to right in each line are a 3D image, 2D image, and profile of the NiTi surface along the direction $\Delta$ - $\nabla$ in the $2 \mathrm{D}$ image; optical profilometry, final treatment (Table 1): (a) chemical etching (A), (b) modification with Zr ion beams (AG), (c) modification with Ti ion beams $(\mathrm{AH}),(\mathrm{d})$ mechanical polishing and electropolishing (B), (e) modification with Ti ion beams (BH), and (f) modification with Si ion beams (BJ). 


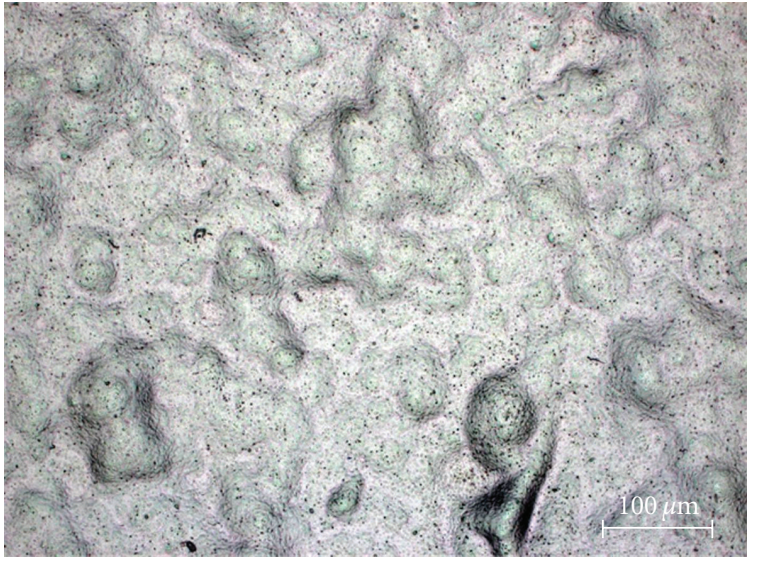

(a)

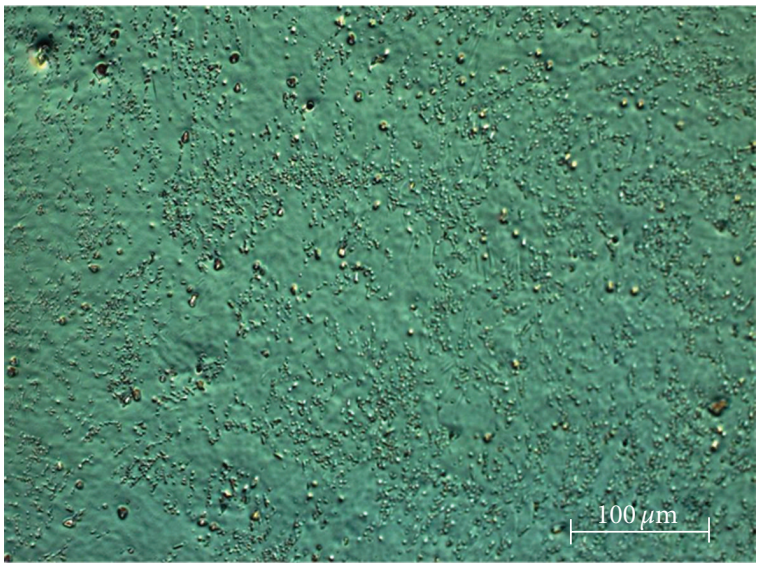

(c)

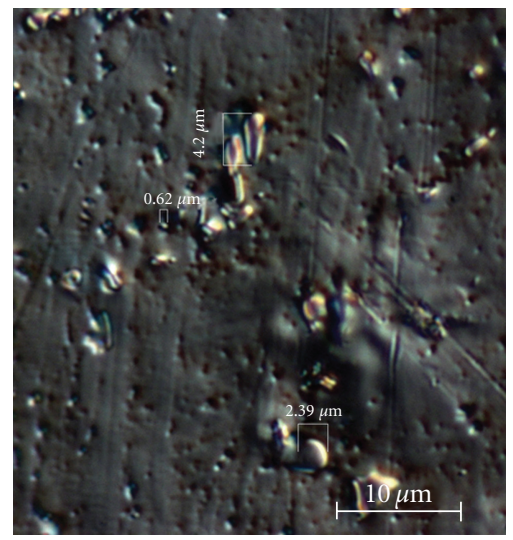

(e)

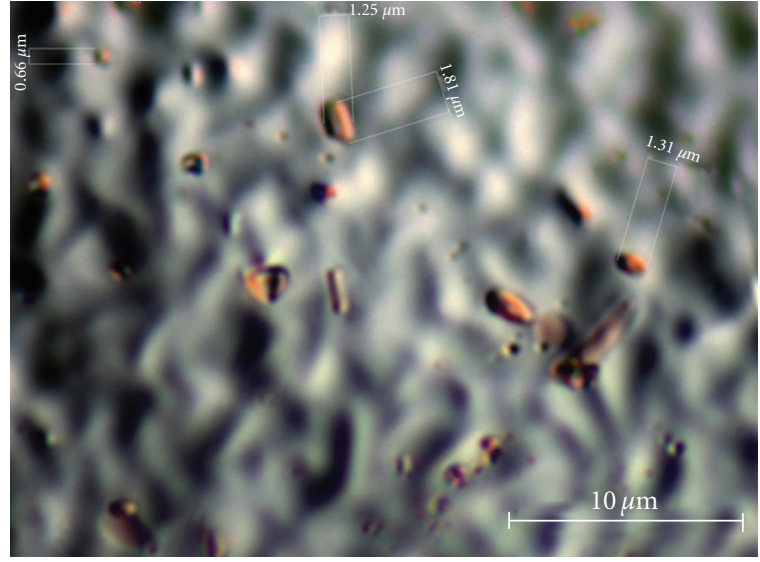

(b)

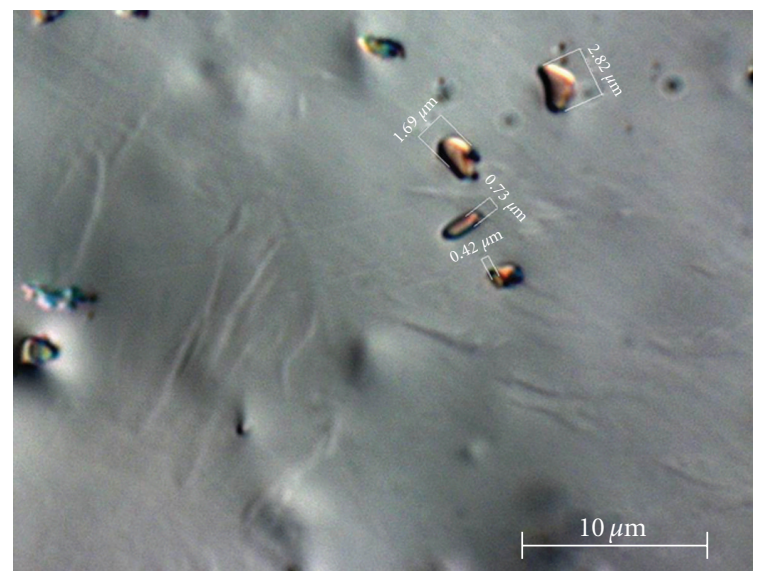

(d)

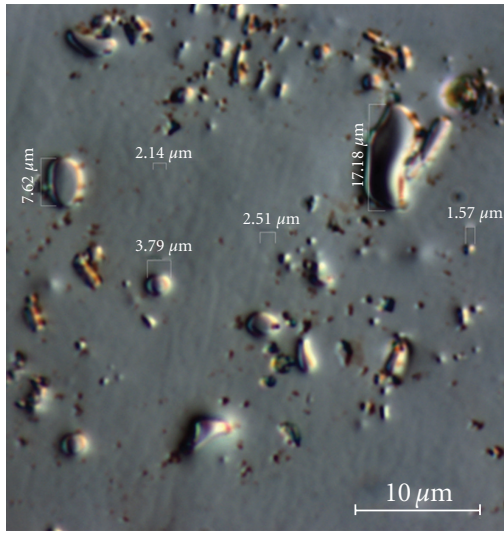

(f)

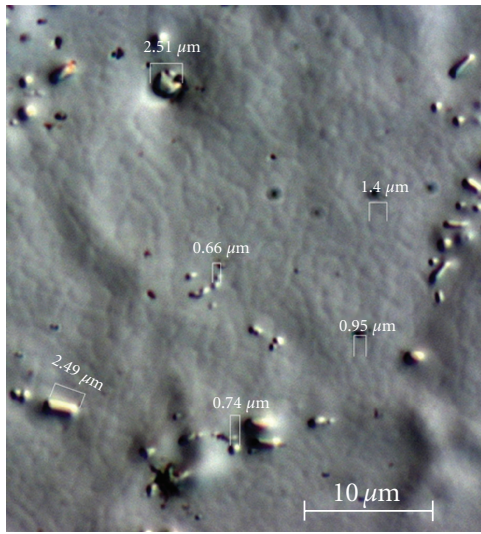

(g)

Figure 5: Optical images of the NiTi specimen surface after different types of treatment (Table 1): chemical etching with subsequent electropolishing (a)-(b), high-luster mechanical polishing with subsequent electropolishing (c)-(d), and ion modifications of the NiTi-B specimens with $\mathrm{Zr}$ ions (e), Ti ions (f), and Si ions (g) of fluence (in all cases) $D=2 \times 10^{17} \mathrm{~cm}^{-2}$.

(A), electrochemical treatment (B), and ion implantation ( $\mathrm{G}$, $\mathrm{H}, \mathrm{J}$ ) shows that the NiTi-A specimens (Figure 4(a)) have the highest roughness and the NiTi-B specimens (Figure 4(d)) have the lowest roughness (Table 2). These two types of treatment result in a characteristic quasiperiodic distribution of asperities and dents with respective average periods of $30-100$ and $5-10 \mu \mathrm{m}$ on the specimen surface. Comparison of digital images (Figure 4), which give quantitative topographic data, and optical images (Figure 5) of the NiTiA specimen surfaces (Figure 4(a), Figures 5(a) and 5(b)) 


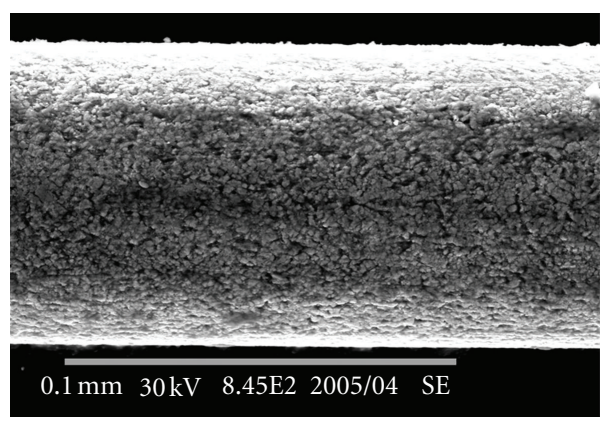

(a)

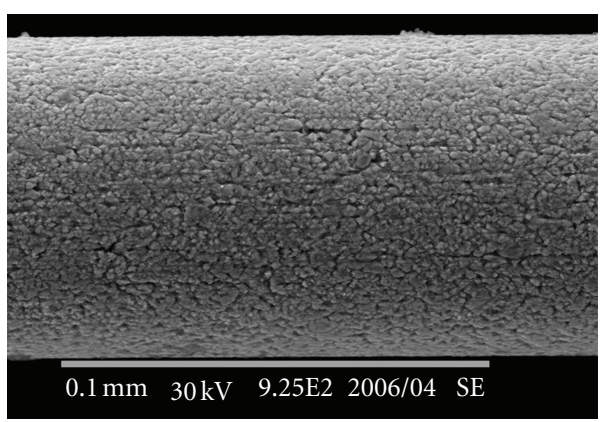

(c)

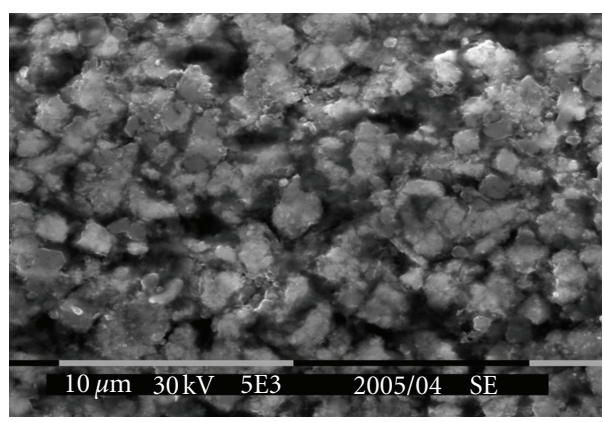

(b)

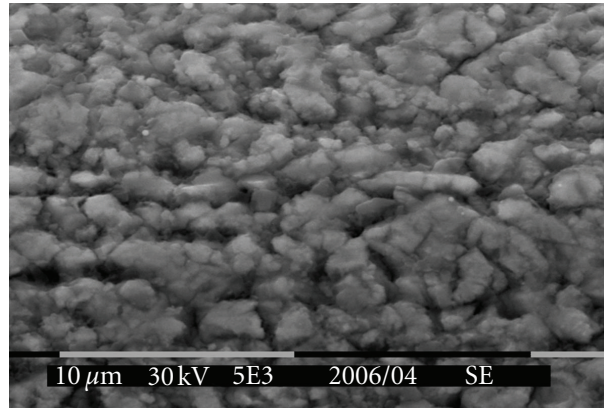

(d)

FIGURE 6: SEM images of the NiTi wire of diameter $90 \mu \mathrm{m}$ before (a), (b) and after (c), (d) high-dose ion implantation with Ti ions of fluence $D=2 \times 10^{17} \mathrm{~cm}^{-2}$ at an average accelerating voltage of $60 \mathrm{kV}$ and pulse repetition frequency of $50 \mathrm{~Hz}$.

and NiTi-B specimen surfaces (Figure 4(d), Figures 5(c) and $5(\mathrm{~d}))$ suggest that the first roughness range $(30-100 \mu \mathrm{m})$ corresponds to the spacings between adjacent grains of the B2 phase of the NiTi alloy, and the second roughness range owes to several factors: particle sizes and interparticle spacing in the $\mathrm{Ti}_{2} \mathrm{Ni}$ phase, width of grain boundaries of the B2 phase revealed in chemical and electrochemical treatments, and irregularities due to the defect distribution nonuniformity on the surface and associated surface etching nonuniformity.

The ion beam treatment, while keeping the primary surface profile, leads to additional fragmentation of the specimen surfaces with a decrease in the size of structural elements (fragments) in the main phase substructure to 100$300 \mathrm{~nm}$ (Figures 4(b), 4(c), 4(e) and 4(f), Figures 5(e)-5(g)). The fragmentation causes the roughness of the smoothest specimens to increase somewhat and that of the initially rough NiTi-A specimens to decrease. It should be noted that a similar, but more pronounced effect is observed in $\mathrm{Zr}$ ion implantation of NiTi-A wires of diameters 60, 90, and $200 \mu \mathrm{m}$ (Figure 6). These changes in the surface profile and morphology of materials irradiated by ions of average energy $\sim 50-60 \mathrm{keV}$ owe to atomic sputtering of the target material [34], including sputtering of both light oxygen and carbon atoms adsorbed at the surface and heavier components of the target material. In this case, the light atoms, as a rule, are removed from the surface, whereas the heavier atoms again precipitate on the surface thus changing their surface distribution and the surface landscape. The number of atomic layers involved in this process can be 100-300 depending on the energy of impacting ions [34]. The energy of impacting ions depends on both the accelerating voltage and the mass of an ion [17]; therefore, the heavier the ion, the deeper the sputtered layer. In irradiation with ion beams of average energy, which were used in our work, atoms of the main target components ( $\mathrm{Ti}$ and $\mathrm{Ni}$ ) are removed forming a plasma cloud of a sort over the target surface, and on completion of the irradiation, they, again settle on the target surface, are uniformly distributed over it, and smooth the initial surface relief. In our viewpoint, it is this mechanism that explain the so clearly defined difference in the roughness of the NiTi-A specimens treated with $\mathrm{Zr}$ and Ti ions (Figures 4(b) and 4(c), resp.) whose atomic masses differ almost twofold $\left(A_{\mathrm{Zr}}=91.224, A_{\mathrm{Ti}}=47.867\right.$ with respect to the mass of a hydrogen atom).

Note that the topographic parameters are of particular importance in studies of biocompatibility of materials with cell cultures, because the cell size and certain of surface roughness parameters are bound to be close to provide favorable conditions for cell proliferation on the surface of a medical material [34].

3.4. Effect of $\mathrm{Zr}$, Ti, and Si Ion Implantation of NiTi Surface Layers on the Proliferative Properties of MSCs. After cultivation of rat MSCs with the unimplanted NiTi-A and NiTi-B specimens and on their surface for $72 \mathrm{~h}$ and 7 and 14 days, no reliable difference was found between the number of living cells in the test and control wells, as evidenced by histograms in Figure 7. It is seen in the figure that the MTT test (Figures $7(\mathrm{a})$ and $7(\mathrm{c})$ ) and standard cell counting in the Goryaev chamber (Figures $7(\mathrm{~b})$ and $7(\mathrm{~d})$ ) gives close 


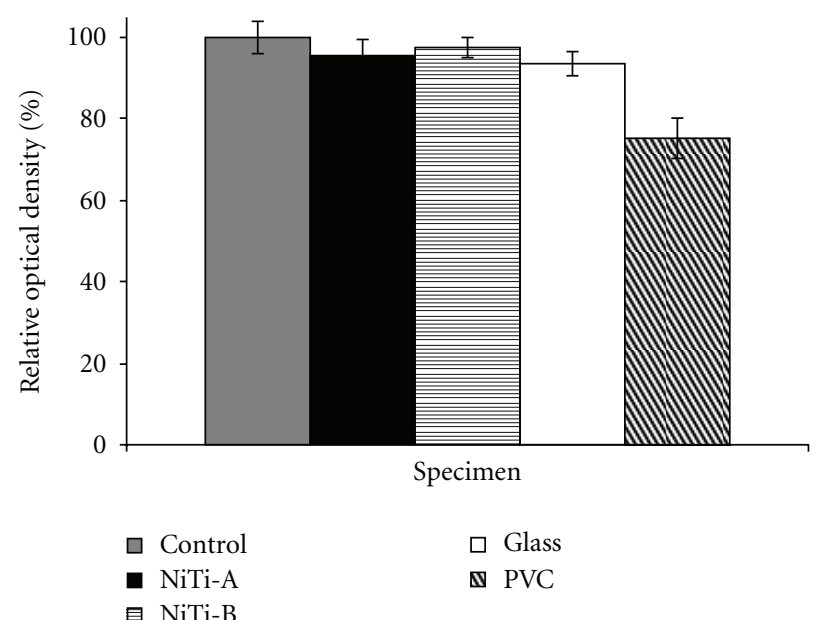

(a)

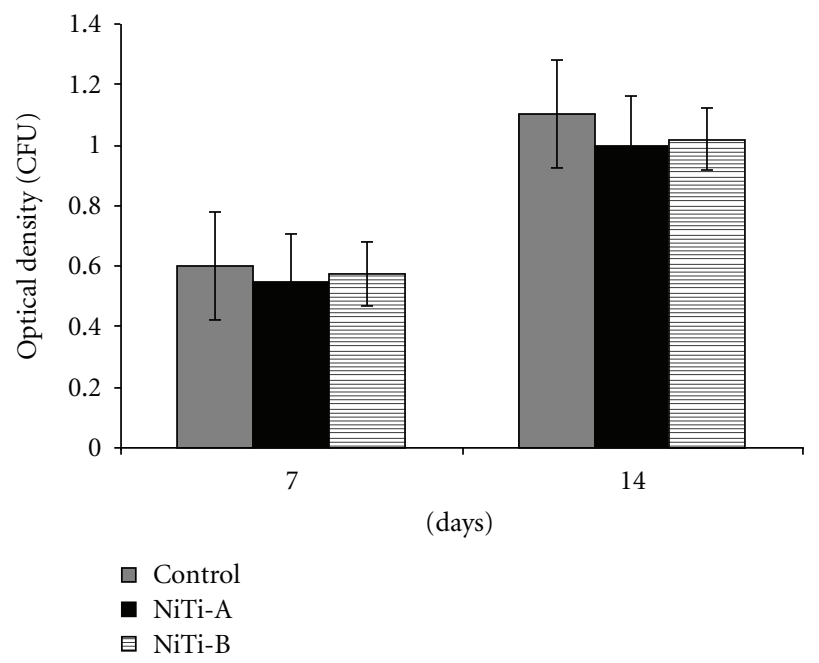

(c)

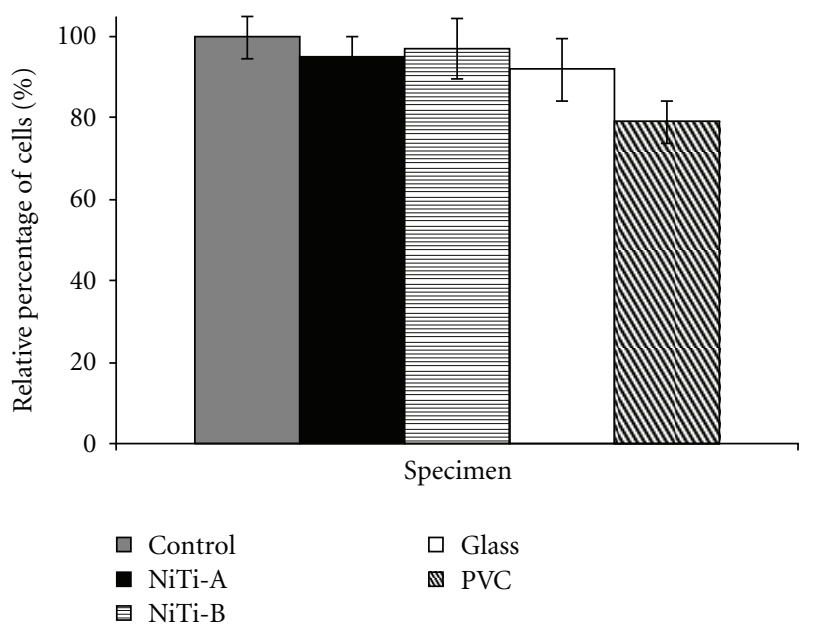

(b)

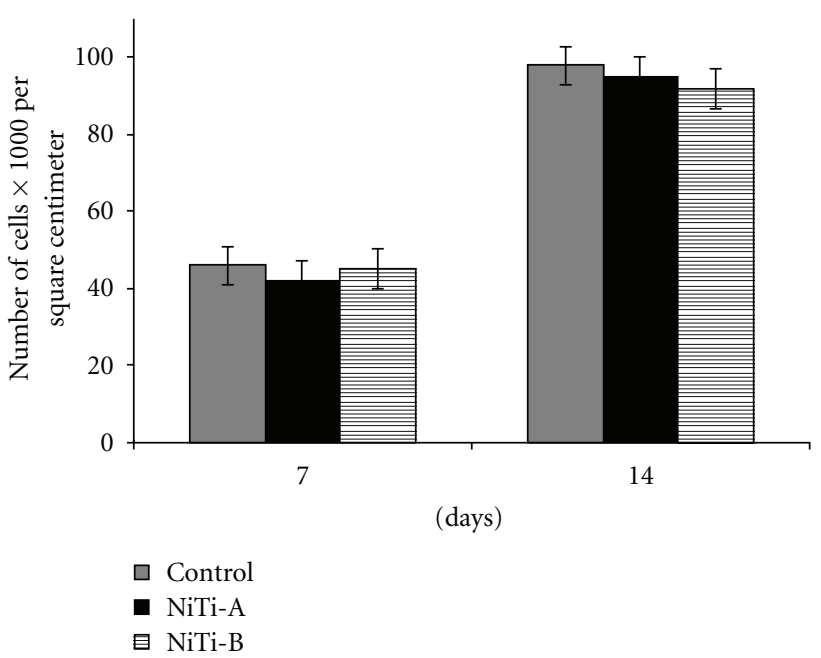

(d)

FIgure 7: Cytotoxicity of the NiTi-A and NiTi-B specimens: MTS assay (a) and cell counting in the Goryaev chamber (b); efficiency of MSC proliferation with the NiTi-A and NiTi-B specimens: MTT test (c) and cell counting in the Goryaev chamber (d).

estimates of viable cells in the culture wells. Analysis of these data also shows that the number of cells contacting the surfaces of the NiTi-A and NiTi-B specimens does not depend on time. Thus, the results in total point to the absence of toxic action of the specimen material on MSC proliferation.

Cultivation of MSCs with the NiTi-AG/AH/AJ and NiTi$\mathrm{BG} / \mathrm{BH} / \mathrm{BJ}$ specimens modified by ion beams (at certain $\mathrm{Zr}$, $\mathrm{Ti}$, and $\mathrm{Si}$ concentrations on the surface) and on the surfaces of these specimens disclosed that the ion beam treatment does not impair the biocompatibility of the specimens in toxicity indices. The modified specimens of all series did not reveal any pronounced toxic action on the cells. This is evidenced by the absence of reliable differences between the number of living cells cultivated with the NiTi specimens and that found in the cell control wells (Figure 8). The living cells estimated in standard cell counting in the Goryaev chamber
(Figure 8(a)) and in the MTT-test (Figure 8(b)) are close in number.

Cultivation with and with no (control wells) ion-implanted specimen also did not reveal any considerable difference in the efficiency of MSC proliferation for all types of the test specimens, as evidenced by cell counting in the Goryaev chamber and in the MTT test (Figure 9). The viability of the cells in all cases was $\sim 95 \%$, and this compares with the viability of the cells cultivated under ordinary conditions without the specimens.

When cultivated with the ion-implanted specimens, the cells were attached to the well surface retaining their fibroblastic morphology and capability for proliferation and formation of colonies. The number of colonies grown with the test specimens was comparable to the number of colonies found in cultivation of the cells without the specimens (Table 3). 


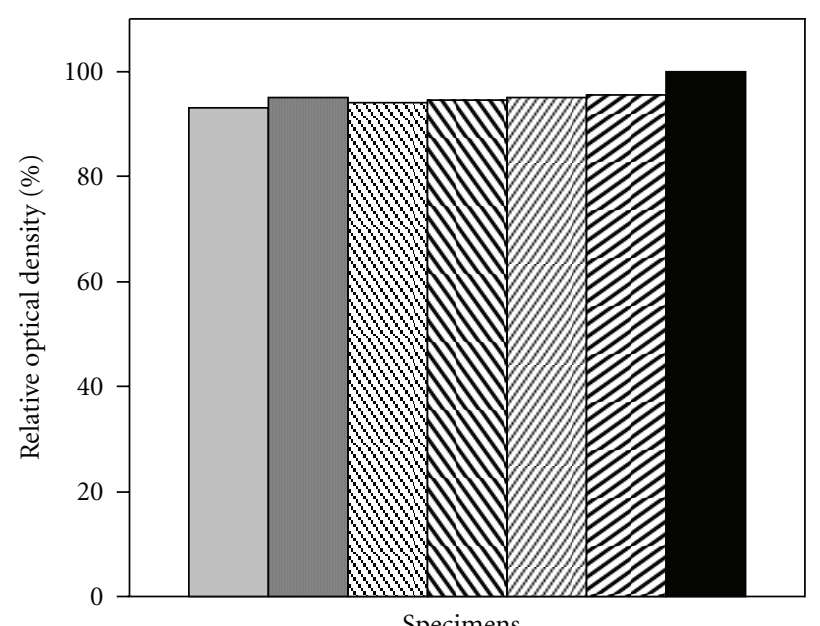

Specimens

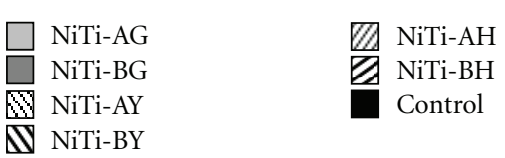

(a)
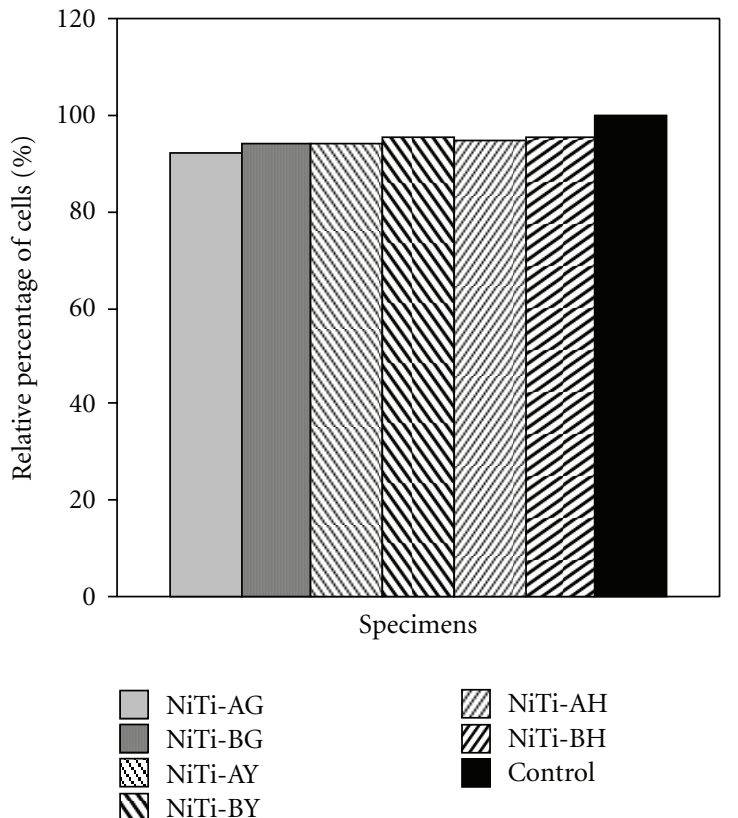

(b)

FIGURE 8: Cytotoxicity of the NiTi specimens differing in surface properties: MTT test (a), cell counting in the Goryaev chamber (b); control cells cultivated with no specimen (cell control wells).

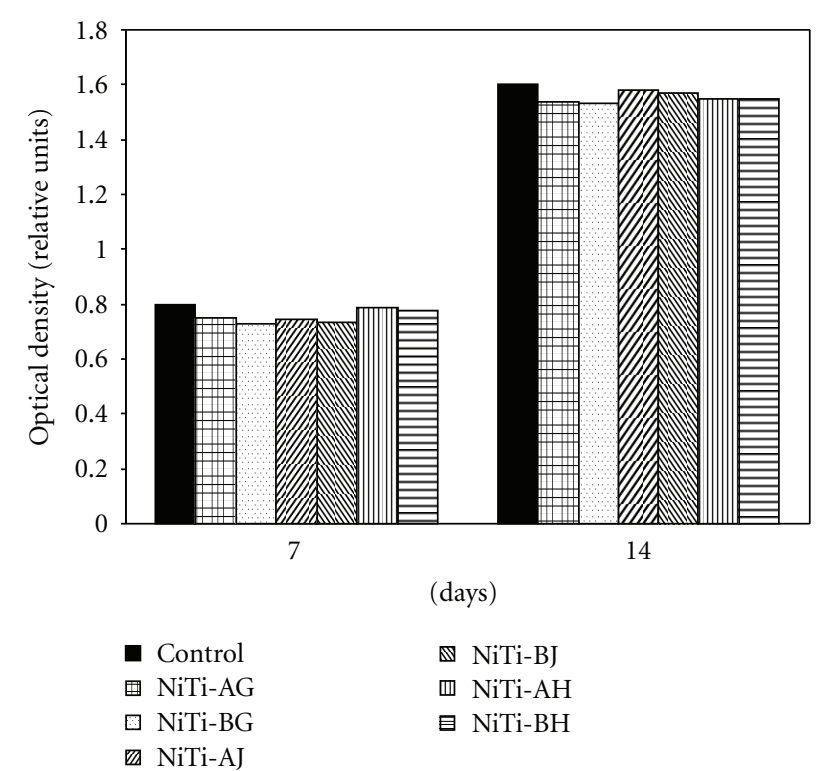

(a)

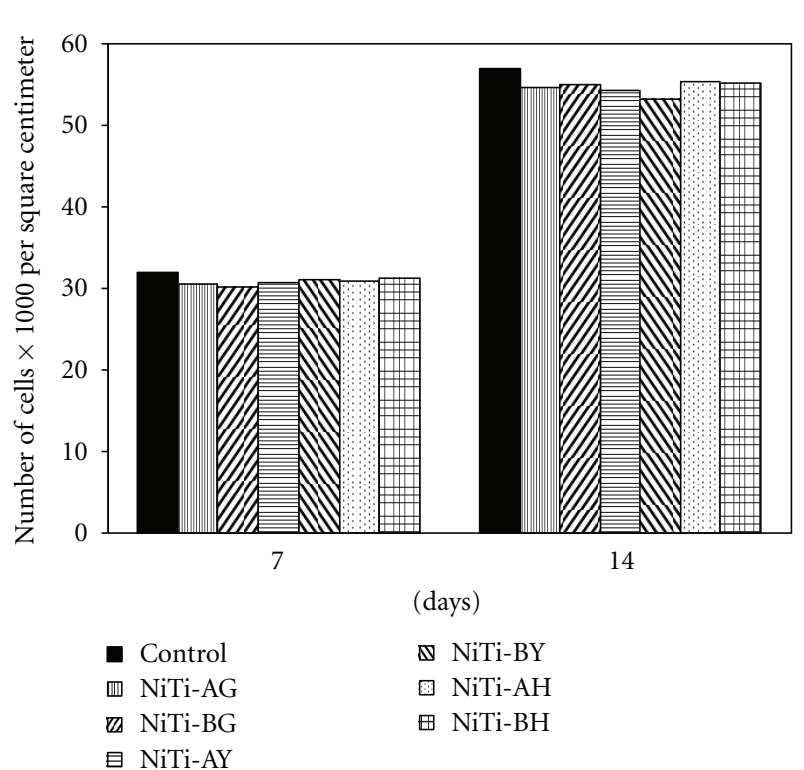

(b)

FIGURE 9: Efficiency of MSC proliferation with the NiTi specimens: MTT test (a), cell counting in the Goryaev chamber (b); control cells cultivated with no specimen (cell control wells).

According to the data of optical microscopy, the MSCs cultivated with the unimplanted NiTi-A and NiTi-B specimens were attached to the well surface retaining their inherent fibroblastic morphology no matter what the cultivation time (Figure 10).
It is found that the surfaces of the NiTi-AG/AH/AJ and $\mathrm{NiTi-BG/BH/BJ} \mathrm{specimens} \mathrm{retained} \mathrm{the} \mathrm{properties} \mathrm{responsi-}$ ble for MSC attachment and proliferation, as evidenced by the formation of MSC colonies on the surfaces detected in fluorescent microscopy (Figure 11). Most of the colonies on 


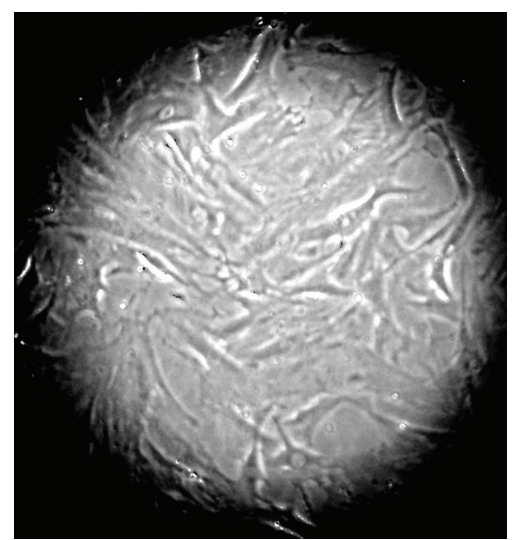

(c)

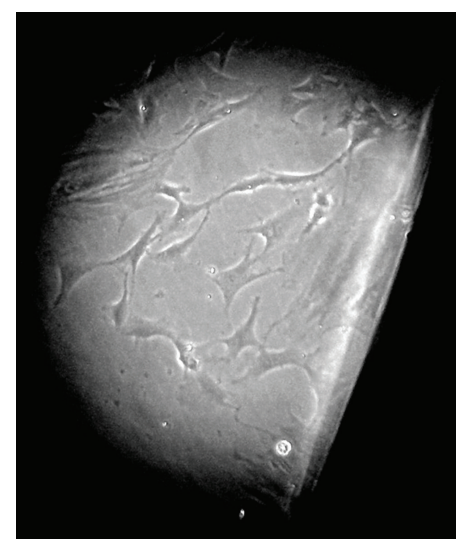

(1a)

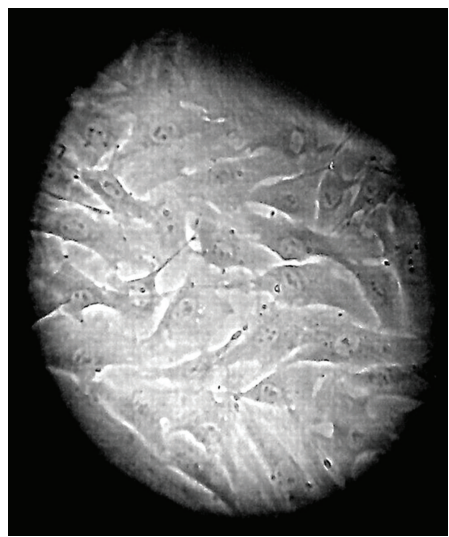

(2a)

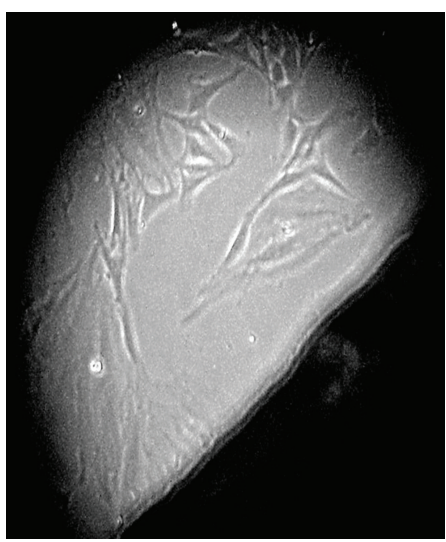

(1b)

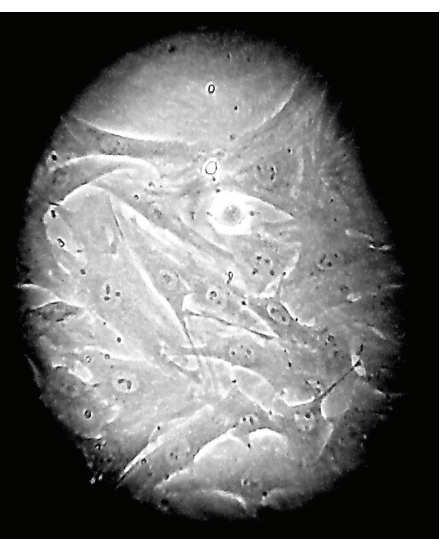

(2b)

FIgURE 10: Morofology of MSCs calctivated with the NiTi-A and NiTi-B specimens: cultivation with no specimen (c), cultivation for 3 days with NiTi-A (1a) and NiTi-B (1b); cultivation for 14 days with NiTi-A (2a) and NiTi-B (2b). Optical microscope, magnification is $\times 50$ for (c), (1a), (1b) and $\times 100$ for $(2 a),(2 b)$.
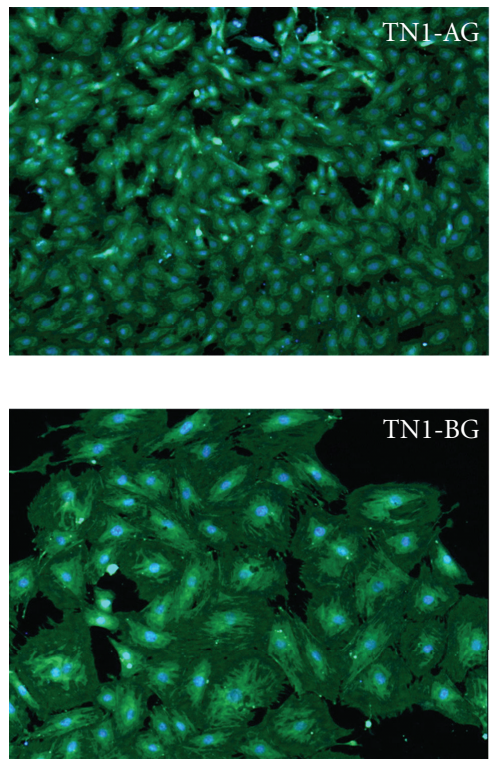

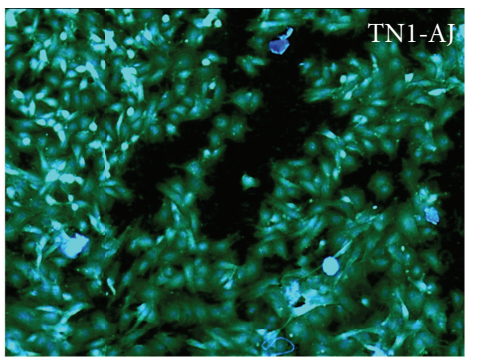

(a)

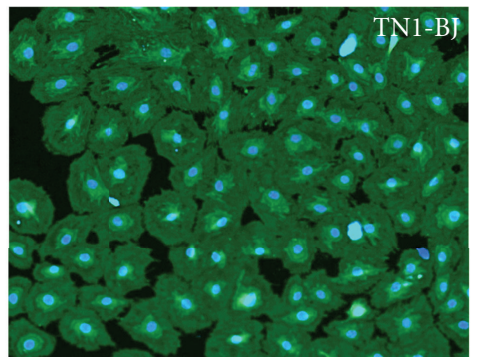

(b)
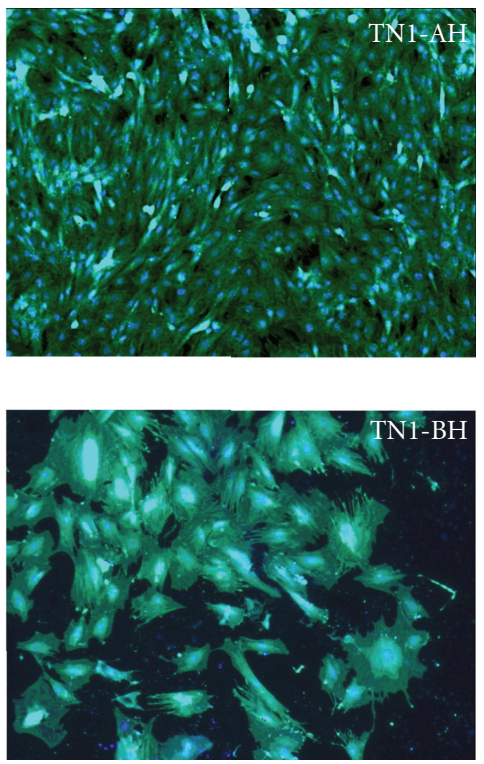

FIGURE 11: Images of fixed MSCs (prevailing colonies) stained with 6-carboxyfluorecein diacetate (6-CFDA) and DAPI on the NiTi specimen surfaces differing in chemical composition and roughness; 14th day of cultivation; magnification is $\times 10$; cells are green, nuclei are blue. 


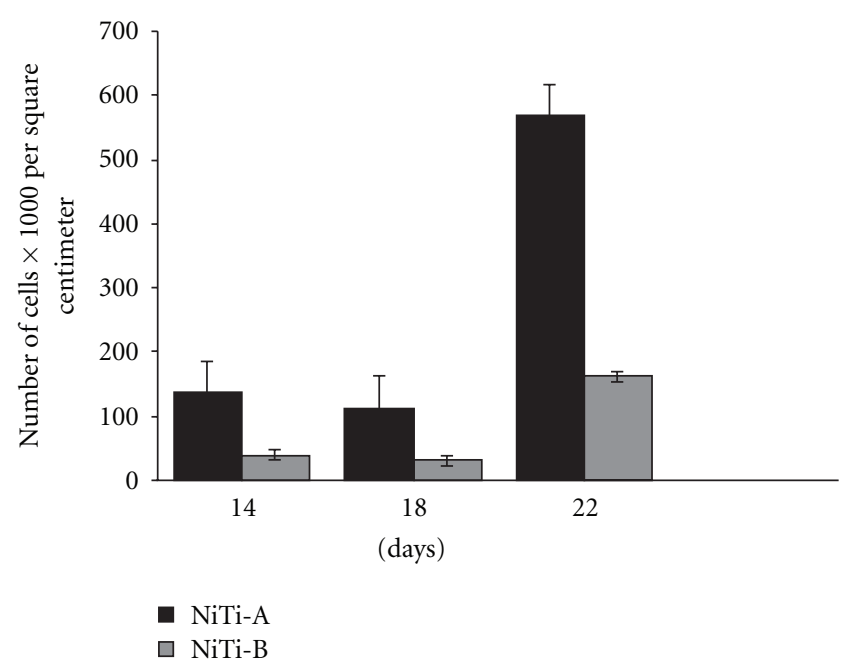

Figure 12: Efficiency of MSC proliferation on the NiTi-A and NiTiB specimens. Cell counting in the Goryaev chamber.

the surfaces of the NiTi-AG/AH/AJ specimens are formed by oblong cells (Figure 11(a)). The surface of the NiTi$\mathrm{BG} / \mathrm{BH} / \mathrm{BJ}$ specimens is dominated by monolayer colonies of varying looseness formed by flattened more round cells (Figure 11(b)). The variety of cell colonies can result from both the peculiarities of the MSC interaction with the specimen material (primarily with its ion-implanted surface layer) and the selection of definite MSC precursors governed by physicochemical and geometric (topographic) properties of the specimen surface.

3.5. Effect of the Surface Roughness of the NiTi Specimens on the Proliferative Properties of MSCs. As noted above, the NiTi-A and NiTi-B specimens differ in surface roughness; the surface roughness of the NiTi-A specimens is of the $\nabla 7$ class and that of the NiTi-B specimens is of the $\nabla 10-11$ class. Study of the efficiency of MSC proliferation on the surfaces of the NiTi-A and NiTi-B specimens identical in chemical composition, but differing in roughness suggests that, with the same cultivation time, the number of attached cells depends on the surface roughness, as evidenced by cell counting in the Goryaev chamber (Figure 12). So, the number of cells on the NiTi-A specimens was larger than that on the NiTi-B specimens. The obtained data agree with the results reported in $[35,36]$ and demonstrate that a rough surface of biomaterials is more prone to cell attachment than a smother one, and this accelerates the cell proliferation on the rough surface.

Fluorescence microscopy analysis shows that the MSCs retain their fibroblastic morphology on the surface of the NiTi-A and NiTi-B specimens (Figures 13(a) and 13(b)); however, the cell distributions over the specimen surfaces are different (Figures 13(c) and 13(d)). On the surface of the NiTi-A specimens, the cells are uniformly distributed forming a near-continuous layer (Figure 13(c)), whereas on the surface of the NiTi-B specimens their population density is lower and the cells form separate colonies (Figure 13(d)).
TABLE 3: Efficiency of the formation of colonies of MSCs cultivated with the NiTi specimens differing in chemical composition and surface roughness. Summarized data for three specimens of each type.

\begin{tabular}{lcc}
\hline Specimen & $\begin{array}{c}\text { Average number of } \\
\text { colonies in a well }\end{array}$ & $\begin{array}{c}\text { Average number of } \\
\text { colonies in a well per } \\
\text { square centimeter }\end{array}$ \\
\hline NiTi-AG & 118 & 14.3 \\
NiTi-AG & 115 & 14.1 \\
NiTi-AJ & 109 & 12.3 \\
NiTi-BJ & 111 & 13.8 \\
NiTi-AH & 116 & 14.9 \\
NiTi-BH & 106 & 13.2 \\
Control & 149 & 14.9 \\
\hline
\end{tabular}

The cell distribution in the form of closed and open cell layers on the specimen surfaces presumably depends on the surface morphology and roughness of the test specimens because, as shown above, their chemical compositions are alike and are nontoxic to MSCs.

The data of fluorescence microscopy of the ionimplanted NiTi-AG/AH/AJ and NiTi-BG/BH/BJ specimens after MSC cultivation demonstrate, among other things, that the largest number of cell colonies is found on the smooth Si-implanted surface (NiTi-BJ specimens), whereas the smooth Zr-implanted surface (NiTi-BG specimens) is least populated by cell colonies (Table 4). The rough $\mathrm{Zr}$ and Si-implanted surfaces (NiTi-AG and NiTi-AJ specimens, resp.) are almost equally populated by cell colonies, but their number is larger than that on the NiTi-BG specimens. The Ti-implanted surfaces, no matter what their roughnessis, are almost identically populated by cell colonies, but their number is larger than that on the surfaces of the NiTi-BG, NiTi-AG and NiTi-AJ specimens and is smaller than that on the surfaces of the NiTi-BJ specimens. In other words, a clearly defined trend toward regular variations of the number of colonies on the specimens is observed depending on the physicochemical and geometric (topographic) properties of the ion-implanted surfaces.

When cultivated with the ion-implanted specimens, the MSCs were attached to the well surface retaining their fibroblastic morphology and capability for proliferation and formation of colonies. The number of colonies grown with the test specimens was comparable to the number of colonies found in cultivation of the cells without the specimens (Table 3). Thus, the test specimens have no effect on the formation of colonies and are nontoxic to the MSCs.

According to the data presented in Table 3, the NiTi specimens have no effect on the formation of colonies and are nontoxic to MSCs. Hence, it can be supposed that different numbers of colonies on the specimen surfaces owes to an individual and unique range of physicochemical, morphological, and topographic properties which were ensured by appropriate surface treatment and which are likely to be responsible for survivability of the cells on the surface: attachment, spreading, and subsequent proliferation. 


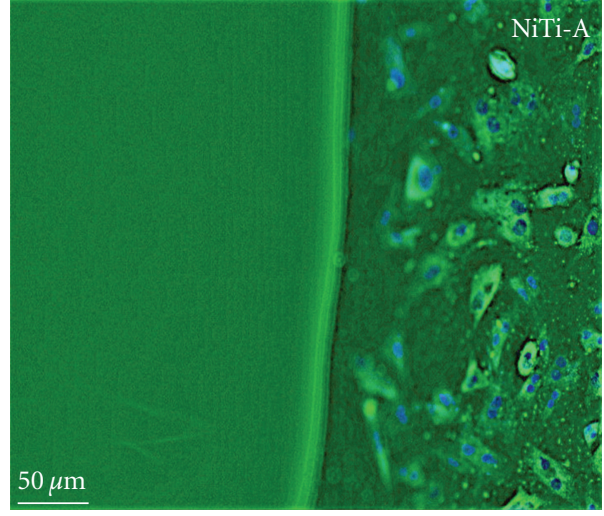

(a)

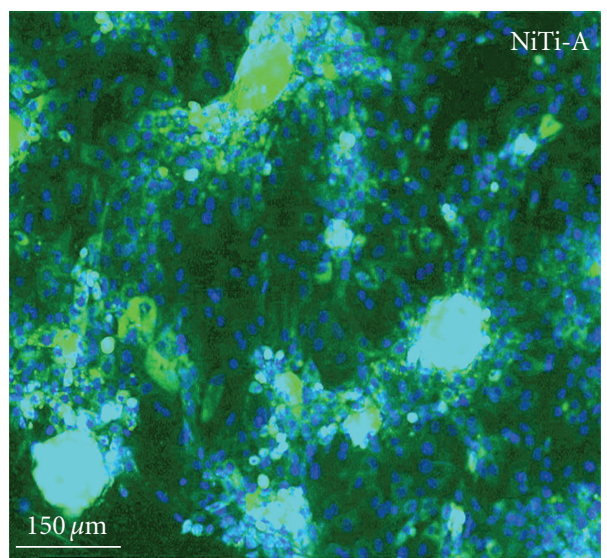

(b)

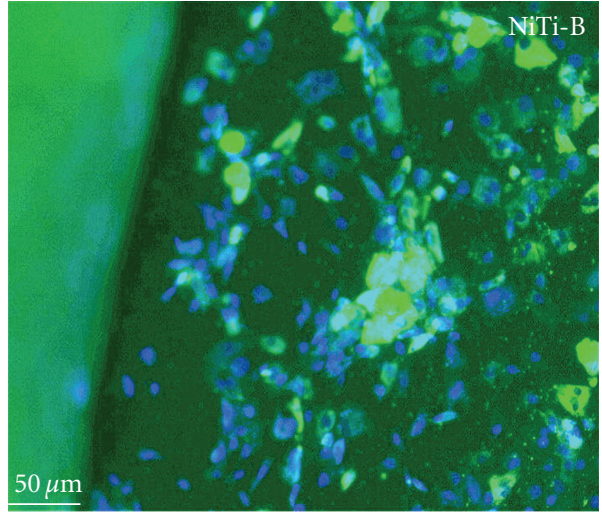

(c)

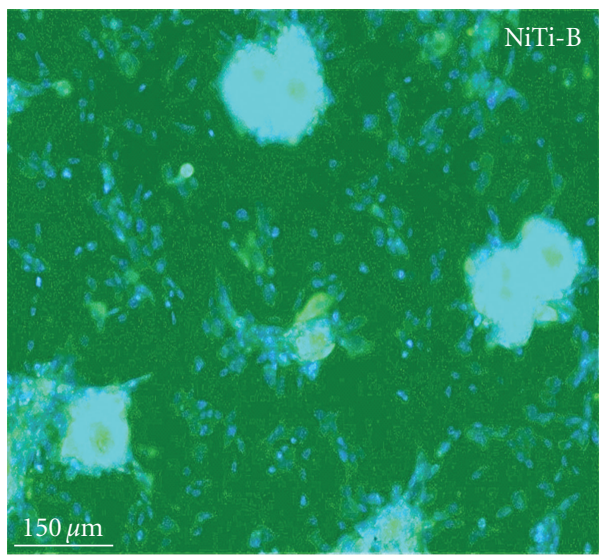

(d)

FIGURE 13: Fluorescence microscopy of MSCs transfected with a eGFP-N1 plasmid DNA on the NiTi-A and NiTi-B surfaces. Nuclei are stained with DAPI; 77th day of cultivation; magnification is $\times 20$ (a), (b) and $\times 10$ (c), (d).

TABLE 4: Efficiency of the formation of colonies of MSCs cultivated on the surface of the NiTi specimens differing in chemical compositions and roughness. Summarized data for three specimens of each type.

\begin{tabular}{|c|c|c|c|c|c|c|}
\hline \multirow[t]{2}{*}{ Specimen } & \multicolumn{5}{|c|}{ Number of colonies } & \multirow[t]{2}{*}{$\begin{array}{c}\text { Number of colonies on the specimen per } \\
\text { square centimeter }\end{array}$} \\
\hline & average for a specimen & small & medium-sized & large & merged & \\
\hline NiTi-AG & 13 & 6 & 1 & 1 & 5 & 3.9 \\
\hline NiTi-BG & 9 & 4 & 3 & 2 & - & 1.6 \\
\hline NiTi-AJ & 20 & 7 & 7 & 4 & 2 & 3.75 \\
\hline NiTi-BJ & 38 & 17 & 15 & 2 & 4 & 7.35 \\
\hline NiTi-AH & 33 & 13 & 14 & 3 & 3 & 4.98 \\
\hline NiTi-BH & 27 & 2 & 16 & 8 & 1 & 5.27 \\
\hline
\end{tabular}

The developed surface roughness of a specimen increases the cell adhesion to the specimen surface [37], because the amount of extracellular matrix adhesion proteins on a rough surface is much larger than that on a smooth one [38]. During the cultivation under the same conditions, the initially rough surface of the NiTi-A specimens presumably adsorbs more protein molecules from the culture medium to involve them in the cell adhesion than the initially smooth surface of the NiTi-B specimens does. At the same time, the degree of adhesion protein adsorption from a serumcontaining culture medium is higher for rough surfaces than for smooth ones [39]. It is conceivable that the level of surface roughness of the NiTi-A and NiTi-AG/AH/AJ specimens with ion-implanted surface layers makes possible an extracellular matrix necessary for cell adhesion with more regular spatial organization compared to that formed on the surface of the NiTi-B and NiTi-BG/BH/BJ specimens with ion-implanted surface layers. As shown in [39], the 
best adhesion and proliferation of cells is furnished by fibronectin molecules whose spatial interrelation owes to roughness due to particles of size $\sim 200 \mathrm{~nm}$ rather than by fibronectin molecules discretely adsorbed on a smooth surface or surfaces of roughness due to particles of different size.

\section{Conclusion}

Thus, the research results allow the following conclusions.

(1) The chemical and physical parameters of the surfaces of all examined specimens suggest that before ion beam treatment the specimens of two NiTi-A and NiTi-B series are alike in chemical composition and are different only in morphology and roughness level. The ion beam treatment changes not only the chemical composition on the specimen surfaces, but also the surface morphology such that the roughness of the smoothest surfaces increases greatly and that of the rougher surfaces, on contrary, decreases.

(2) The experiments demonstrate that neither the unimplanted NiTi-A and NiTi-B specimens, nor the ion-implanted NiTi-AG/AH/AJ and NiTi-BG/BH/BJ specimens reveal cytotoxic action on rat MSCs. Moreover, it is shown that the chemical composition of the NiTi specimen surfaces before and after ion implantation does not produce any damaging action on MSCs. At the same time, the experiments suggest that the NiTi-A and NiTi-B specimens fail to stimulate the proliferation of MSCs and this allows the assumption of bioinertness of their surface layers. On contrary, the NiTi-AG/AH/AJ and NiTi-BG/BH/BJ specimens with ion-implanted surface layers reveal properties favorable for proliferation of MSCs on their surfaces. Detailed studies of these specimens are expected in the near future.

\section{Acknowledgments}

The work was performed under projects of SB RAS no. III.20.3.1 and 57 and was supported by state Contract of the Ministry of Education and Science of the Russian Federation no. 16.740.11.0140.

\section{References}

[1] S. A. Abugov, M. V. Puretsky, P. A. Rudenko et al., "Endovascular stenting of bifurcation stenosis in patients with ischemic heart disease," Kardiologia, no. 8, pp. 7-11, 1998 (Russian).

[2] A. V. Sidelnikov, "Comparative evaluation of long-term effects of coronary artery stenting with a Crossflex wire stent and transluminal balloon angioplasty in IHD patients" (Russian), Candidate dissertation in medicine, Moscow, Russia, p. 20, 2002.

[3] I. I. Kornilov, O. K. Belousov, and E. V. Kachur, Titanium Nickelide and Other Shape Memory Alloys, Nauka, Moscow, Russia, 1977.

[4] A. I. Lotkov, V. N. Khachin, V. N. Grishkov, L.L. Meisner, and V. P. Sivokha, "Shape memory alloys," in Physical
Mesomechanics and Computer-Aided Design of Materials, vol. 2, pp. 202-213, Nauka, Novosibirsk, Russia, 1995.

[5] V. N. Zhuravlev and V. G. Pushin, Thermomechanical Shape Memory Alloys and Their Application in Medicine, UrB RAS, Ekaterinburg, Russia, 2000.

[6] L. L. Meisner, "Mechanical and physicochemical properties of NiTi-based alloys with thin surface layers modified by charged particle flows," Physical Mesomechanics, vol. 7, part 2, pp. 169$172,2004$.

[7] A. I. Lotkov, L. L. Meisner, and V. N. Grishkov, "NiTi-based alloys: ion-beam, plasma, and chemical surface modification," Fizika Metallov i Metallovedenie, vol. 99, no. 2, pp. 1-13, 2005 (Russian).

[8] D. Williams, Biocompatibility of Clinical Implant Materials, CRC Press, Boca Raton, Fla, USA, 1981.

[9] S. A. Shabalovskaya, J. Anderegg, F. Laab, P. A. Thiel, and G. Rondelli, "Surface conditions of NiTinol wires, tubing, and as-cast alloys. The effect of chemical etching, aging in boiling water, and heat treatment," Journal of Biomedical Materials Research: Part B, vol. 65, no. 1, pp. 193-203, 2003.

[10] V. I. Sevostianov, Ed., Biocompatibility, 1999.

[11] V. P. Shakhov, I. A. Khlusov, G. S. Dambaev et al., "Methods of analysis of cellular cultures, artificial organs, and biomaterials," in Introduction into Methods for Cell Culture, Bioengineering of Organs and Tissues, pp. 340-349, STT, Tomsk, Russia, 2004.

[12] N. A. Korzh, L. A. Kladchenko, and S. V. Malyshkina, "Implant materials and osteogenesis. Role of optimization and stimulation in bone repair," Orthop. Traum. Protez., no. 4, pp. 5-14, 2008 (Russian).

[13] E. V. Vladimirskaya, O. A. Maiorova, S. A. Rumyantsev, and A. G. Rumyantsev, "Stem cells and intercellular interactions," in Biological Basis and Prospects of Stem Cell Therapy, pp. 74-102, Medpraktica-M, Moscow, Russia, 2005.

[14] S. A. Kuznetsov, A. J. Friedenstein, and P. G. Robey, "Factors required for bone marrow stromal fibroblast colony formation in vitro," The British Journal of Haematology, vol. 97, no. 3, pp. 561-570, 1997.

[15] D. C. Miller, K. M. Haberstroh, and T. J. Webster, "PLGA nanometer surface features manipulate fibronectin interaction for improved vascular cell adhesion," Journal of Biomedical Materials Research: A, vol. 81, pp. 678-684, 2006.

[16] S. M. Chesnokov, "Wide-aperture ion source," RF patent number RU 1598757, registered in the State Register 16.11.93.

[17] V. P. Sergeev, V. P. Yanovsky, and Yu. N. Paraev, "Extended ion source," RF patent number RU 2261497, Bulletin of inventions number 27, 2005.

[18] A. I. Lotkov, S. G. Psakhie, and V. P. Sergeev, "Formation of nonequilibrium states in surface layers of materials by electron-ion plasma technologies," in Surface Nanoengineering, N. Z. Lyakhov and S. G. Psakhie, Eds., pp. 227-275, Publishing house of SB RAS, Novosibirsk, Russia, 2008.

[19] D. I. Potter, M. Ahmed, and S. Lamond, "Microstructural developments during implantation of metals," in Proceedings of the Ion Implantation and Ion Beam Processing of Materials, vol. 27 of Materials Research Society Symposia Proceedings, pp. 117-126, 1984.

[20] J. K. Hirvonen, Ed., Ion Implantation into Metals, Metallurgia, Moscow, Russia, translation from English edited by O. P. Elyutin, 1985.

[21] L. Clapham, "High dose, heavy ion implantation into metals: the use of sacrificial surface layers to enhance retention," Surface and Coatings Technology, vol. 65, no. 1-3, pp. 24-29, 1994. 
[22] M. Nastasi, J. W. Mayer, and J. K. Hirvonen, Ion-Solid Interactions: Fundamentals and Applications, vol. XXVII of Cambridge Solid State Science Series, Cambridge University Press, Cambridge, UK, 1996.

[23] T. Mosmann, "Rapid colorimetric assay for cellular growth and survival: application to proliferation and cytotoxicity assays," Journal of Immunological Methods, vol. 65, no. 1-2, pp. 55-63, 1983.

[24] T. Yu. Tatarenko-Kozmina, Pathophysiological mechanisms of application of mesenchymal stem cells on synthetic composites for optimization of bone tissue regeneration, Doctoral dissertation in biology, Moscow, Russia, 2007.

[25] N. A. Plokhinsky, Biometry, MSU Publishing House, Moscow, Russia, 1970.

[26] A. G. Akimov, "On the mechanisms of the formation of protective oxide layers in "metal (alloy)-medium" systems," Zashchita Metallov, vol. XXII, no. 6, pp. 879-886, 1986 (Russian).

[27] L. L. Meisner, V. P. Sivokha, A. I. Lotkov, and E. G. Barmina, "Corrosion resistance of quasibinary NiTi-TiAu alloys in biochemical solutions," Fiz. Khim. Obr. Mater., no. 1, pp. 78 84, 2006 (Russian).

[28] S. A. Shabalovskaya, H. Tian, J. W. Anderegg, D. U. Schryvers, W. U. Carroll, and J. V. Humbeeck, "The influence of surface oxides on the distribution and release of nickel from Nitinol wires," Biomaterials, vol. 30, no. 4, pp. 468-477, 2009.

[29] L. L. Meisner, V. P. Sivokha, A. I. Lotkov, and L. A. Derevyagina, "Surface morphology and plastic deformation of the ion-implanted TiNi alloy," Physica: B, vol. 307, no. 1-4, pp. 251-257, 2001.

[30] L. L. Meisner, V. P. Sivokha, A. I. Lotkov, and E. G. Barmina, "Effect of ion implantation on shape memory characteristics of TiNi alloy," Journal de Physique IV, vol. 112, pp. 663666, 2003, Proceedings of the International Conference on Martensitic Transormations, (ICOMAT '020), Espoo, Finland, June, 2002.

[31] L. Tan, R. A. Dodd, and W. C. Crone, "Corrosion and wearcorrosion behavior of NiTi modified by plasma source ion implantation," Biomaterials, vol. 24, no. 22, pp. 3931-3939, 2003.

[32] A. I. Lotkov and A. A. Baturin, "Vacancy defects in metals, alloys, and intermetallic compounds with martensite transformations," Materialovedenie, no. 7, pp. 39-44, 2000.

[33] F. V. Nolfi, Ed., Phase Transformations during Irradiation, Metallurgia, Chelyabinsk, Russia, Translated from English by M. E. Reznitsky, V. M. Ustintschikov, and A. B. Tsepelev, Edited by L.N. Bystrov, 1989.

[34] B. D. Ratner and A. S. Hoffman, "Physicochemical surface modification of materials used in medicine," in Biomaterials Science: An Introduction to Materials in Medicine, B. D. Ratner, Ed., pp. 201-218, Elsevier, 2nd edition, 2004.

[35] K. Anselme, "Osteoblast adhesion on biomaterials," Biomaterials, vol. 21, no. 7, pp. 667-681, 2000.

[36] E. Eisenbarth, P. Linez, V. Biehl et al., "Cell orientation and cytoskeletion organization on ground titanium surfaces," Biomolecular Engineering, no. 19, pp. 233-237, 2002.

[37] R. A. Pareta, A. B. Reising, T. Miller, D. Storey, and T. J. Webster, "An understanding of enhanced osteoblast adhesion on various nanostructured polymeric and metallic materials prepared by ionic plasma deposition," Journal of Biomedical Materials Research: Part A, vol. 92, no. 3, pp. 1190-1201, 2010.

[38] J. Marleta, J. Uptonac, R. Langerbo, and J. P. Vacantica, "Transplantation of cells in matrices for tissue regeneration," Advanced Drug Delivery Reviews, no. 3, pp. 165-182, 1998.
[39] D. C. Miller, K. M. Haberstroh, and T. J. Webster, "Mechanism(s) of increased vascular cell adhesion on nanostructured poly(lactic-co-glycolic acid) films," Journal of Biomedical Materials Research: Part A, vol. 73, no. 4, pp. 476-484, 2005. 

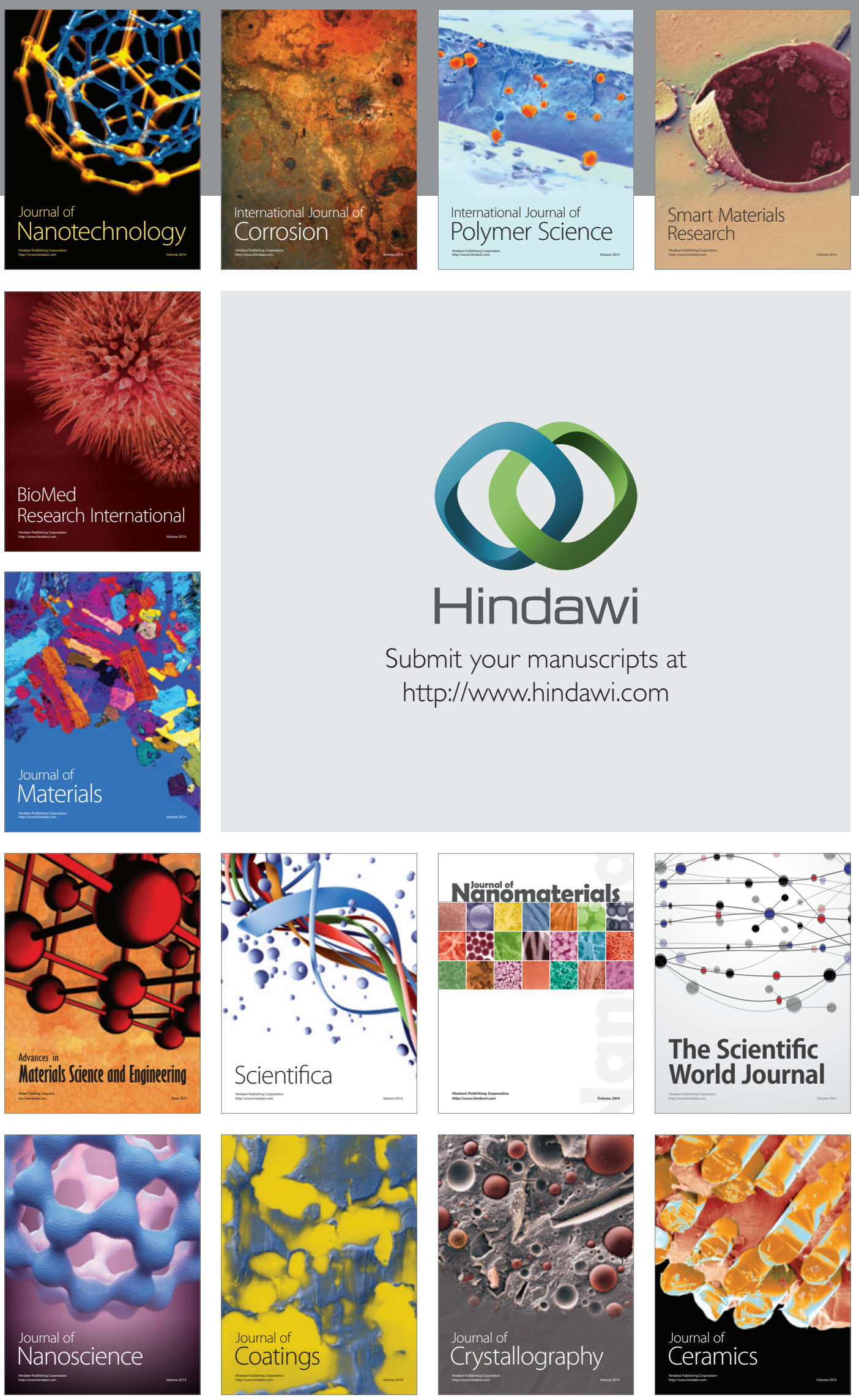

The Scientific World Journal

Submit your manuscripts at

http://www.hindawi.com

\section{World Journal}

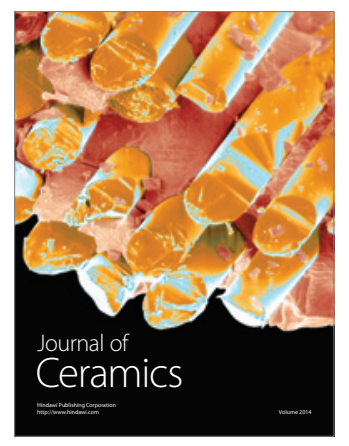

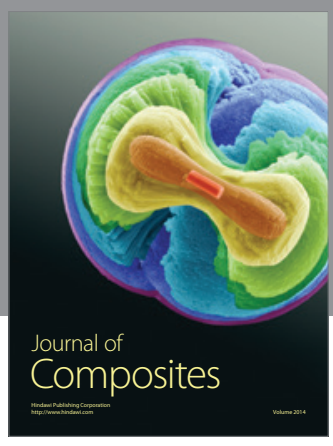
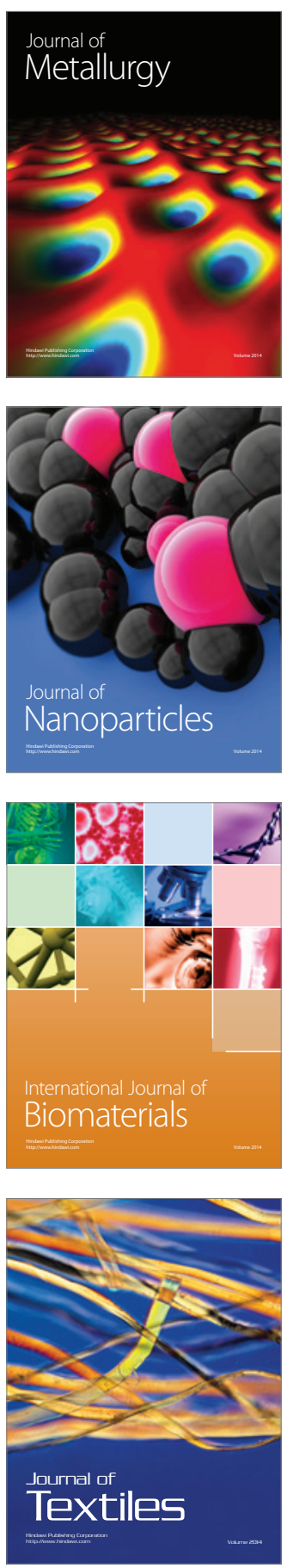